\title{
The effects of residual gas trapping on part load performance and emissions of a spark ignition direct injection engine fuelled with wet ethanol
}

Thompson Diórdinis Metzka Lanzanova*1, Macklini Dalla Nora', Mario Eduardo Santos Martins', Paulo Romeu Moreira Machado', Vinícius Bernardes Pedrozo², Hua Zhao

${ }^{1}$ Grupo de Pesquisa em Motores Combustíveis e Emissões (GPMOT), Federal University of Santa Maria - Roraima Av. 1000, Santa Maria, Brazil, 97105-900

${ }^{2}$ Centre for Advanced Powertrain and Fuels (CAPF), Brunel University London - Kingston Lane, Uxbridge, United Kingdom, UB8 $3 \mathrm{PH}$

*Corresponding author: lanzanova@gmail.com

\section{Highlights:}

- $\quad$ Stable engine operation was achieved with $20 \%$ water-in-ethanol (v/v) and $40 \%$ residual gas fraction;

- $\quad$ Negative valve overlap provided hot residual gas trapping and increased indicated efficiency;

- Higher combustion efficiency was achieved with intermediate RGF between 25-30\%;

- Water dilution was more effective in reducing NOx emissions than residual gas trapping;

\section{Keywords:}

- Wet Ethanol

- $\quad$ Negative valve overlap

- Hot residual gas

- Variable valve actuation

\begin{abstract}
:
Biofuels, such as ethanol, have been introduced as a solution to decrease total $\mathrm{CO}_{2}$ emissions from transport sector as well as an alternative to increase the domestic energy security against international fuel price fluctuations. The use of high water content ethanol, the so-called wet ethanol (ethanol with higher than $5 \%$ water content $v / v$ ), has been proposed to reduce ethanol production cost. This work presents the application of wet ethanol on a naturally aspirated direct injection single cylinder research engine equipped with a fully variable electro-hydraulic valve train running on stoichiometric air/fuel ratio. The negative valve overlap (NVO) strategy was used to retain high residual gas fraction (RGF) at the part load operation of 3.1 bar IMEP and $1500 \mathrm{rpm}$. Anhydrous ethanol and different wet ethanol compositions ( $10 \%$ and $20 \%$ water-in-ethanol content v/v) were tested
\end{abstract}


for several NVO durations, as well as European RON 95 gasoline. A one-dimensional engine model was built and validated against experimental data to estimate the RGF for each operating point. It was possible to achieve stable stoichiometric operation with more than 35\% RGF for anhydrous ethanol and RON 95 gasoline. On the other hand, the maximum supported RGF for stable operation decreased as the water-in-ethanol content increased. The increase in water content reduced the tolerance to hot residuals due to lower combustion temperatures, which lengthened the flame initiation and main combustion phases. Even then, the increase in NVO period resulted in net indicated efficiency gains for all fuels due to less pumping losses, lower combustion temperature, and the possibility to maintain combustion efficiency at acceptable levels even with the maximum achievable RGF of each fuel. Anhydrous ethanol presented the highest net indicated efficiencies, while $10 \%$ water-in-ethanol mixture presented slightly higher indicated efficiency compared to gasoline. $20 \%$ water-in-ethanol mixture provided the lowest indicated efficiencies over the whole range of tested RGF.

\section{Introduction}

Greenhouse gas (GHG) emissions are considered one of the major contributors to global warming and climate change. The transportation sector accounts for about $25 \%$ of the total carbon dioxide $\left(\mathrm{CO}_{2}\right)$ emissions in the European Union (EU) and about $30 \%$ in the United States (US) [1], [2]. New gaseous emission and fuel economy legislations have been introduced to limit the amount of $\mathrm{CO}_{2}$ produced by light-duty vehicles in the EU, US, Japan, China, and other countries. In addition to developing high efficiency internal combustion engines, low carbon and renewable fuels can be effective on reducing $\mathrm{CO}_{2}$ emissions. In particular, sustainable utilization of a fuel requires the analysis of the well-to-wheel energy expense by production and total $\mathrm{CO}_{2}$ production. In this scenario, the use of alternative fuels with positive energy balance in production and low carbon footprint such as ethanol would be an advantage.

Ethanol is a biofuel produced from the starch fermentation of agricultural crops. The first generation ethanol production is centred on crop plantation, mashing and cooking, sugar fermentation, distillation, and dehydration. The second-generation ethanol production is based on the conversion of cellulose into fermentable molecules, with the following steps: fermentation, distillation, and dehydration. The first generation ethanol represents the largest share of worldwide produced ethanol and typically has a positive net energy balance. Regarding greenhouse gas emissions, ethanol production and consumption is more efficient and attractive than that presented by fossil fuels. When assessing ethanol's energy production process, it has been shown that wet ethanol with more than $10 \%$ water can save a considerable amount of energy and reduce its production costs [3]-[6]. Ladisch and Dyck [3] investigated the energy dispended during the distillation process of ethanol. They showed that the ratio of available fuel energy to energy expended during distillation process decreases abruptly at almost 10 times to remove 
the remaining $10 \%$ water-in-ethanol content. More recently, Flowers et al. [4] proposed the use of hydrous ethanol with more than $10 \%$ water-in-ethanol (so called wet ethanol) as internal combustion engines' fuel. Later, López-Plaza et al. [5] studied the energy gains and possible $\mathrm{CO}_{2}$ reduction on the wet ethanol production chain when using several distillation scenarios. Another study [6] investigated in deep the wet ethanol production process to determine the effect on energy use, water consumption and greenhouse gas (GHG) emissions in the refining stage of the corn ethanol lifecycle. This study showed that a $10 \%$ (v/v) waterin-ethanol fuel would reduce the energy expense in about $10 \%$, with monetary savings and energy reduction of around $8 \%$. Thus, ethanol-in-water mixtures have been investigated as an alternative low cost biofuel [7]-[10]. A catalytic igniter was proposed to enable stable SI operation with up to $30 \%(v / v)$ water-in-ethanol on an SI engine of a transit van [7], [8]. The authors have also investigated the use of wet ethanol on spark ignition engines [9], [10] and found that the optimum ethanol-in-water content for the lowest engine operation cost is between $15 \%$ and $10 \%$ water-in-ethanol.

A study focused on a small SI power generator running on wet ethanol [11], [12] showed that the increase in water content reduced the overall engine efficiency and increased unburned hydrocarbon $(\mathrm{HC})$ and aldehyde emissions. Nitrogen oxides (NOx) emissions were reduced by approximately $80 \%$ when the water content was increased from $20 \%$ to $40 \%$ v/v. The catalytic converter allowed for reasonable reduction in terms of emissions under stoichiometric operation. Severe wearing of engine parts and oil lubricant contamination were reported. No combustion analysis was presented.

In another study [13], the application of wet ethanol containing up to $20 \%$ of water on a mass basis ( $\mathrm{m} / \mathrm{m}$ ) was investigated in a supercharged four-cylinder direct injection (DI) engine. In terms of tank-to-wheels emissions, carbon monoxide (CO), $\mathrm{CO}_{2}$, and NOx were unaffected by the increase in water-in-ethanol content. HC emissions increased linearly with the increase in water-inethanol content. Brake efficiency could be maintained at some particular high load conditions. Advanced spark timing was required to compensate for the longer combustion processes of wet ethanol with higher water content.

A more recent study [14] reported that wet ethanol with $10 \%$ water resulted in faster combustion than anhydrous ethanol when operating the engine with a constant intake air pressure at a low load of approximately 1.5 bar net indicated mean effective pressure (IMEP). The investigation was performed in a single cylinder optical engine equipped with DI and port fuel injection (PFI) systems. The use of water-in-ethanol fractions of more than $10 \%$ further reduced the combustion duration under a PFI operation but yielded a longer combustion process under DI operation. This has been attributed to the higher level of droplet diffusion burn in the flame development images when compared to the PFI operation. The optical results showed that the increase in water content decreased the flame distortion and corrugation. Other combustion visualization study showed that the longer combustion duration resulted from lower apparent flame speed of high water-in-ethanol fuels provided more time 
for flame front distortion caused by in-cylinder flow characteristics[15]. Iso-octane combustion duration was larger than anhydrous ethanol but faster than any wet ethanol mixture.

Other concerns raised for wet ethanol engine operation are the possible wall wetting with PFI systems and fuel impingement with DI systems. The occurrence of these events can reduce combustion efficiency due to increased unburned HC and aldehyde emissions.

In addition, studies have explored the use of wet ethanol in homogeneous charge compression ignition ( $\mathrm{HCCl}$ ) combustion [4], [16]-[20] and, more recently, in dual-fuel reactivity controlled compression ignition (RCCI) combustion [21], [22]. High fuel conversion efficiencies and low NOx emissions were achieved. While $\mathrm{HCCl}$ retains combustion control limitations despite recent development made by Mazda [23], the RCCl strategy requires a costly compression ignition engine and aftertreatment systems. An alternative approach using a pre-chamber spark ignition (SI) combustion has demonstrated stable engine operation with wet ethanol containing up to $40 \%$ water in a volume basis (v/v) [9], [24].

Alternatively, the use of negative valve overlap (NVO) through the early closure of the exhaust valves has been proposed as an effective means of trapping hot residuals and promoting $\mathrm{HCCl}$ and/or controlled auto-ignition (CAI) combustion. In particular, experiments have reported the formation of highly active radicals that enhance the auto-ignition process when direct injecting fuel during the NVO recompression phase [25]-[27]. This fuel reforming promoted by the hot residuals has showed no benefit in increasing the $\mathrm{HCCl} / \mathrm{CAl}$ operation range with wet ethanol [16], [17]. Nevertheless, wet ethanol direct injection during the NVO period can potentially be used to improve wet ethanol vaporisation and thus fuel conversion efficiency on SI engines.

Several different VVA mechanisms were developed in the last decades to enable different degree of valve actuation freedom. Although fully variable valve actuation (FVVA) mechanisms are already available for production engines, such systems are considerably more expensive. Therefore, only part of the market adopts it based on a cost benefit scenario to attend fuel consumption legislation. In general, the larger the vehicle, the higher the valve actuation freedom necessary to help to achieve $\mathrm{CO}_{2}$ emissions legislation.

One of the most basic variable valve actuation mechanisms is based on cam profile switching (CPS), initially proposed by Honda with its VTEC system. It has two discrete intake cams with different profiles designed for low load/speed (small lift and shorter duration) and high load/speed (high lift and larger duration) [28]. These systems provide low load higher efficiency by partial dethrottling which reduces pumping work (the term de-throttle is used to denote wider throttle opening while unthrottled is used to denote WOT condition with load control through other means than throttling). Another basic mechanism is cam phasing, which may increase or decrease valve overlap, for example [29]. Many manufacturers use both systems at the same time in order to achieve more benefits [30]. 
Other systems based on camshafts, which provide a larger degree of valve actuation freedom, are the so called continuously variable valve lift (CVVL) systems. These systems provide both cam phasing and valve lift freedom. Several mechanisms have been proposed, among them, the most famous are the BMW Valvetronics [31], [32], Schaeffler UniAir [33], [34] (used by FIAT Chrysler), and Nissan Variable Valve Event and Lift (VVEL) system [35]. Three dimensional cam lobes have also been used by Ferrari and Alfa Romeo [36].

Lastly, fully flexible variable valve actuation (FVVA) systems not based on camshafts (camless) have been also developed. These systems can be electro-hydraulic [37], [38], electro-pneumatic [39], or electro-magnetic [40]. They provide fully independent valve actuation with the possibility of two/four-stroke operation in the same engine [41]. Even though it is a promising technology for light duty vehicles, only the electro-pneumatic based system from Freevalve has been implemented in high end production engines [39].

Despite the current research carried out in wet ethanol SI engines, the effects of residual gas trapping on part load performance and emissions have not yet been evaluated for stoichiometric SI operation. In this study, various residual gas fractions, also referred to as internal exhaust gas recirculation (iEGR), were investigated in order to maximise fuel conversion efficiency and minimise exhaust emissions. The NVO strategy was used to improve the vaporisation of the water present in wet ethanol and promote better combustion conditions than those of a conventional throttled SI engine operation. Combustion characteristics, engine-out emissions, and performance of a single cylinder DI camless engine operating with two wet ethanol mixtures (E90W10 and E80W20, where ExxWyy is a water-ethanol mixture containing "xx" percent in volume of ethanol and " $y y$ " percent in volume of water) were compared to those attained with anhydrous ethanol (E100) and unleaded European gasoline (GRON95).

\section{Experimental Setup}

\subsection{Engine specifications and experimental facilities}

The engine used in the experiments was a Ricardo Hydra Camless SI engine equipped with DI system and an electro-hydraulic fully variable valvetrain (FVVT). The engine specifications are presented in Table 1 while the test cell setup is showed in Figure 1. The FVVT provided the capability of independent control of the four valves. For this reason, the engine was capable of operating in both two or four-stroke modes [41], [42]. The spark and injection timings, as well as valve parameters, were controlled through a Ricardo rCube engine control unit (ECU). 
Table 1 - Ricardo Hydra Camless single cylinder engine specifications.

\begin{tabular}{lll} 
Engine Specifications \\
\hline Bore x Stroke \\
\hline Swept Volume \\
\hline Combustion Chamber
\end{tabular}

Figure 1. Engine test cell setup. Symbols containing $T$ and $P$ represent thermocouples and pressure transducers, respectively. The $\lambda$ symbol represents the wide band universal exhaust gas oxygen (UEGO) sensor.

The engine was coupled to an alternate current dynamometer that enabled motoring and firing tests. The engine test cell had closed loop control over coolant and oil temperatures, which were maintained at $363 \mathrm{~K} \pm 2 \mathrm{~K}$. An Endress+Hauser Promass $83 \mathrm{~A}$ Coriolis meter was used to measure fuel flow rate $\left(\dot{m}_{f u e l}\right)$. Fuel temperature was maintained at $298 \pm 5 \mathrm{~K}$. Fuel injection pressure was held constant at $145 \pm 5$ bar. Fuel was directly injected into the cylinder by a multi-hole injector mounted on the side of the cylinder head (between the intake and exhaust valves). The near horizontally positioned spray was located in the core of the reversed tumble flow produced by the upright intake port. Intake air mass flow rate $\left(\dot{m}_{\text {air }}\right)$ was measured by a Hasting HFM-200 laminar flow meter. Intake air temperature was kept at $303 \pm 5 \mathrm{~K}$.

The in-cylinder pressure was measured by a Kistler 6061B piezoelectric pressure sensor. Intake and exhaust pressures were measured by Kistler piezoresistive absolute pressure sensors 4007BA20F and 4007BA5F, respectively. An encoder with 720 pulses per revolution, directly connected to the crankshaft, was used to relate pressure data to crank angle. K-type thermocouples were used to collect average temperatures at relevant locations, such as intake and exhaust manifolds, oil and 
coolant galleries, fuel rail, and valvetrain oil supply. An in-house high speed data acquisition and combustion analysis system was used to monitor and record all parameters.

\subsection{Data analysis}

Exhaust emissions of $\mathrm{CO}, \mathrm{HC}$, and NOx emissions were measured using a Horiba MEXA-7170 DEGR analyser. It is important, however, that the flame ionization detector (FID) outputs are corrected for their lower responsiveness to unburned organic species containing oxygen to carbon bonds. These gaseous emissions are typically constituted by aldehydes and unburned ethanol when the engine is fuelled with ethanol [12], [43]. The correction methodology was presented by Kar et al. [44] where

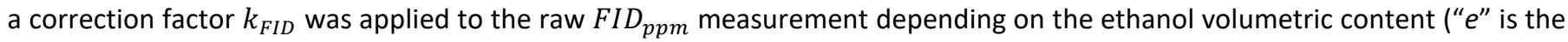
ethanol volumetric content on the mixture) in the fuel [44], [45]. Correction constants of 0.60 and 0.68 for the FID response towards acetaldehyde and ethanol, respectively, were proposed by Wallner et al. [45]. A singular response factor of 0.64 was used in this study, as it represents the average between the response factors of such species. Therefore, the total hydrocarbons (THC) emissions were calculated using the following equations in order to determine the corrected unburned organic and HC emissions:

$T H C=F I D_{p p m} k_{F I D}$

$k_{F I D}=\frac{1}{1-(1-0.64)\left(0.608 e^{2}+0.092 e\right)}$

The procedures presented in the EU Emission Regulation [46] were followed for the calculations of the indicated specific emissions as well as for the conversion of $\mathrm{CO}$ and NOx to a wet basis. The water content present in some of ethanol fuels tested was introduced into the calculations of the dry to wet correction factor $k_{w}$, which corrects for the induced water due to air humidity. The specific NOx humidity correction factor, which aims at eliminating the charge humidity effect on NOx formation due to local-to-local and day-to-day temperature and humidity variations, was not applied. The use of such correction factor would increase the NOx emissions, masking the effect of a deliberately higher charge "humidity" introduced by the wet ethanol. The indicated specific gaseous emissions of each exhaust components evaluated $\left(I S g a s_{i}\right)$ were calculated by:

$\operatorname{ISgas}_{i}=\frac{u_{i}\left[x_{i}\right] k_{w} \dot{m}_{\text {exh }}}{P_{I}}$

where $u_{i}$ and $\left[x_{i}\right]$ are the raw gas exhaust factor [46] and the concentration in ppm for the $i$ chemical element in the exhaust flow, respectively; $k_{w}$ is the dry to wet correction factor applied to CO and NOx; $\dot{m}_{\text {exh }}$ is the exhaust mass flow rate calculated as the sum of the instantaneous fuel and air mass flow rates; and $P_{I}$ is the net indicated power. 
The gas exchange efficiency was calculated as the ratio of work between the entire cycle work (e.g. IMEP) to the power phase work (e.g. compression and expansion strokes only). The power phase work can be considered as the difference between IMEP and pumping mean effective pressure (PMEP).

$\eta_{g e}=\frac{I M E P}{I M E P-P M E P}$

The combustion efficiency expressed how much of the fuel energy was converted into heat. It was calculated from the THC and CO emissions and their lower heating values as

$\eta_{c}=1-\frac{\dot{m}_{C O} L H V_{C O}+\dot{m}_{T H C} L H V_{T H C}}{\dot{m}_{f} L H V_{f}}$ (5)

where $L H V_{f}$ is the lower heating value of the fuel. The gross thermodynamic efficiency $\left(\eta_{t h}\right)$ indicated the efficiency of converting the heat released into work during the power generation phase as

$\eta_{t h}=\frac{W_{c}}{\eta_{g e}\left(\eta_{c} \dot{m}_{f} Q_{L H V_{f}}\right)}$

where $W_{c}$ is the total work produced in one cycle.

Finally, the net indicated efficiency $\left(\eta_{i}\right)$ expressed how much energy from the fuel was actually converted into gas work, which also related all other efficiencies as:

$\eta_{i}=\frac{W_{c}}{\dot{m}_{f} Q_{L H V_{f}}}=\eta_{t h} \eta_{g e} \eta_{c}$

\section{Methodology}

\subsection{Valve timing strategies}

Experiments were performed with NVO valve strategy at an engine speed of $1500 \pm 10 \mathrm{rpm}$ and a part load condition of $3.1 \pm$ 0.1 bar IMEP. According to previous studies at similar loads [41], [47]-[49], two of the most promising valve timing strategies for four stroke low load gasoline combustion operation were the negative valve overlap (NVO) and exhaust gas rebreathing. Although the exhaust gas rebreathing strategy previously investigated by other authors resulted in better indicated efficiency, they also report that combustion efficiency was impaired [41], [47], [48]. As the impact of the water content was expected to further reduce the combustion efficiency [12], [50], this work is focused on the use of the NVO strategy. The longer NVO periods were achieved by advancing the exhaust valve closing (EVC) and delaying the intake valve opening (IVO), as depicted in Figure 2. This allowed for an increase in hot residual gas trapping, which can be beneficial for the combustion process of high water 
content ethanol fuels. For comparison purposes, a conventional SI valve timing strategy, referred to as positive valve overlap (PVO), was used as baseline. In this case, both EVC and IVO events occurred near firing top dead centre (TDC).
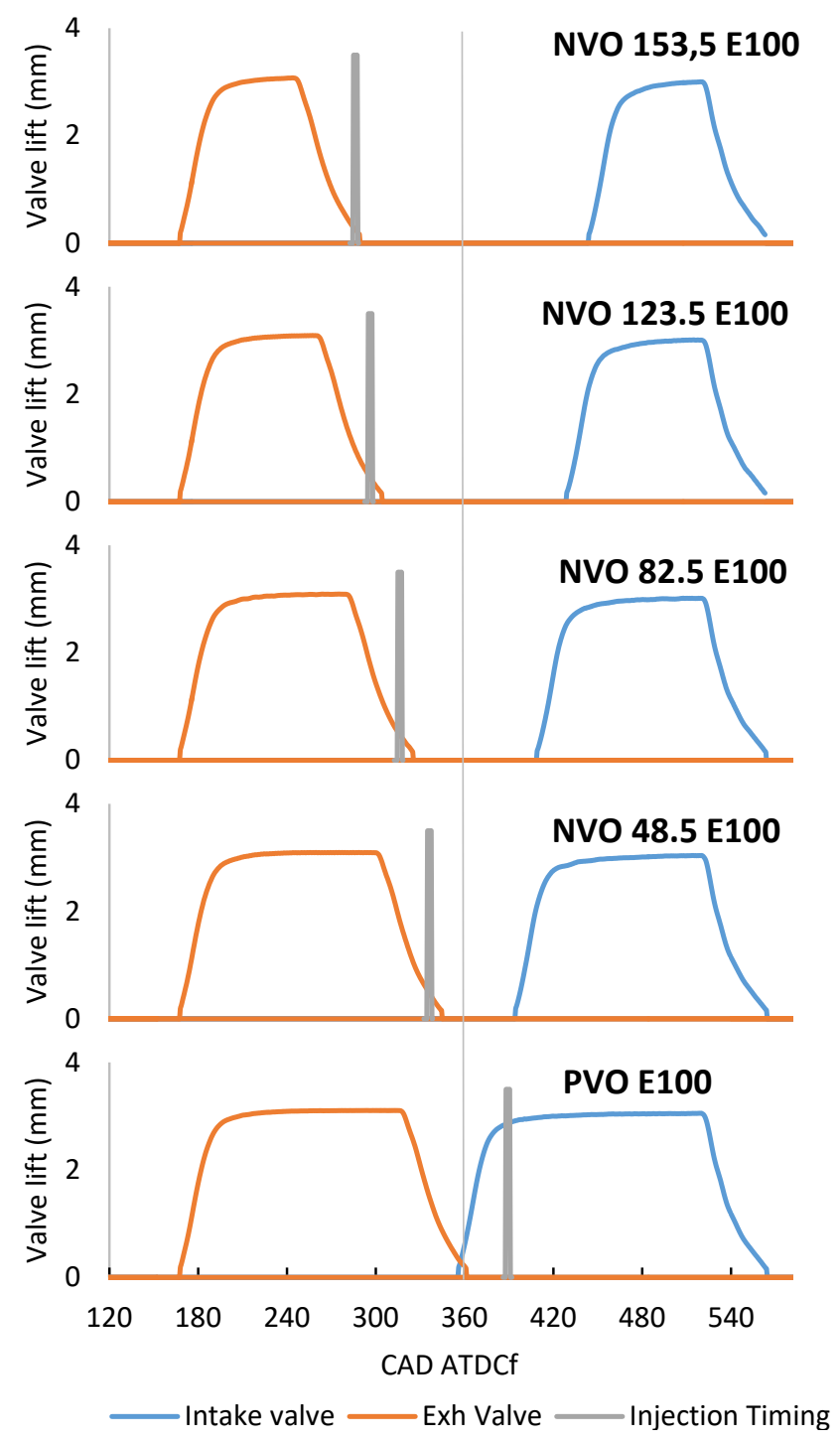

Figure 2. Representation of the negative valve overlap (NVO) and conventional positive valve overlap (PVO) strategies.

During the PVO strategy, part of the burned gas is pushed into the intake manifold due to pressure differential across the cylinder. This is caused by the throttled intake flow (e.g. low intake pressure). By the time the intake pressure overcomes the in-cylinder pressure, this portion of burned gas is sucked back into the cylinder and forms part of the charge for the next cycle. In addition, some exhaust gases can return from the exhaust manifold into the combustion chamber prior to EVC. Typically, the residual gas fraction (RGF) achieved by conventional PVO varies between $10 \%$ and $20 \%$ [51]. The PVO injection timing was set to 32 crank angle degrees (CAD) ATDC as this has been demonstrated as the optimum injection timing for best indicated efficiency in the PVO mode on this engine [52]. 
The early EVC event, attained with the use of NVO strategy, allowed for hot residual gas trapping. The trapped residual gas was recompressed and expanded until the retarded IVO event. The EVC and IVO events occurred with asymmetrical interval to TDC to reduce pumping losses. NVO durations ranging from 45 CAD to 155 CAD were tested to investigate the effect of the hot RGF dilution combined with the water dilution in the wet ethanol combustion. The direct result from the variation of NVO period by the modification of the EVC and IVO while keeping EVO and IVC constant is the modification of valve event durations. The injection timing for the cases with NVO was set to the beginning of the NVO period in an effort to use the high temperatures achieved during the recompression of the trapped residuals.

The mass of residual gas $\left(m_{R G}\right)$ was estimated using a GT-Power engine model and used to calculate the RGF. The model validation is discussed in the next section.

$R G F=\frac{\dot{m}_{R G}}{\dot{m}_{\text {air }}+\dot{m}_{\text {fuel }}+\dot{m}_{R G}}$

\subsection{Test procedure}

Starting from the PVO strategy, the IVO was gradually delayed (after TDC) while the EVC was advanced (before TDC). The NVO duration was increased in steps of approximately 20 CAD, with increments of 10 CAD for the earlier EVC and later IVO. The air/fuel ratio was maintained at stoichiometric conditions by adjusting the intake valve throttled position. The maximum valve lift was controlled at $3.0 \mathrm{~mm}$ for both intake and exhaust valves during the whole set of tests. The effects of low valve lift on EIVC load control was previously investigated in the same engine [53]. Lower valve lifts would increase pumping losses and required longer intake durations to keep a constant load. Adversely, higher valve lifts reduced pumping losses and shortened intake duration for a constant load. Thus, indicated efficiency was slightly reduced for lower valve lifts when compared to higher valve lifts at the same load. Considering this aspect, $3.0 \mathrm{~mm}$ valve lift was chosen instead of the maximum valve lift due to safety issues and to keep a possible and constant valve lift throughout all the tests. If a higher valve lift would be used, there would be the possibility for valve-piston contact for the conventional SI throttled load controlled strategy. Furthermore, the effect of higher valve lift would be applied to all cases in the similar way. In addition, EVO and IVC were kept constant for all tested conditions. Thus, the effect of EVC and IVO could be considered apart from other effects as the dynamic compression ratio variation due to IVC variation, for example. A coefficient of variation of IMEP (COV imep) of less than $5 \%$ over 100 consecutive cycles was used to quantify the engine operation stability.

The ethanol-water mixtures were produced following the splash blending method. A certain volume of ethanol was mixed with

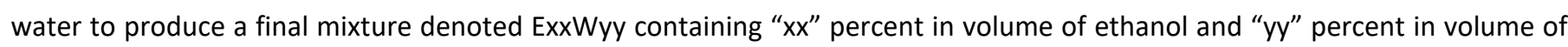


water. Thus, the adopted nomenclature for a mixture of $80 \%$ ethanol and $20 \%$ water was referred to as E80W20. A bulb alcoholmeter was used to measure the final volume of ethanol-in-water at $293 \mathrm{~K}$. The lower heating value (LHV) of the ethanolwater mixtures was calculated using the densities of each liquid and a LHV of $26.9 \mathrm{MJ} / \mathrm{kg}$ for ethanol. The LHV for water was set to zero while commercial European unleaded 95 RON gasoline was considered to have a LHV of $42.5 \mathrm{MJ} / \mathrm{kg}$.

\section{Engine modelling}

\subsection{The engine model}

A one-dimensional (1D) engine model was built on GT-Power to estimate engine parameters such as in-cylinder gas temperature and RGF. The software uses the finite difference method to solve the unsteady compressible flow equations governing the conservation of mass, momentum, and energy. The simulation uses thermodynamic gas properties, including equilibrium composition for the burned gases, and enables the characterisation of the pulsating flows that occur in the engine [54], thus, enabling more accurate estimation of RGF than that obtained using empirical models. All engine pipes were measured, while cylinder head port geometry was taken from engine models. Discharge coefficient of intake and exhaust ports were taken from the cylinder head manufacturer (Ricardo UK), as provided in Appendix A. Geometric parameters of the intake and exhaust systems are also presented in Appendix A.

A two-zone in-cylinder model (burned and unburned charge zones) with a modified Woschni in-cylinder heat transfer sub-model provided by the software was used. The actual heat release rate was calculated taking into account the necessary fuel energy released per CAD to increase the in-cylinder pressure from the previous crank angle to the next simulation crank angle. Instantaneous intake pressure (acquired with a Kistler piezoresistive absolute pressure transducer 4007BA20F) was taken as boundary condition in the intake side which was modelled up to the plenum (where the pressure transducer was installed). The whole exhaust system was modelled and atmospheric boundary condition was set in the end of the exhaust pipe. This modelling methodology is called three pressure analysis (TPA): intake, exhaust and in-cylinder pressure were used to better estimate gas exchange process and residual gas fraction (instead of using only in-cylinder pressure and temperature at a certain crank angle), and in-cylinder pressure was is also used to estimate fuel burn rate. This way, TPA estimates the fuel burn rate for the simulation to present the same pressure behaviour during combustion as that of the experiments, while also accounting for heat transfer (Woschni in-cylinder heat transfer model)[55]. A two-zone model was used for the in-cylinder combustion process separating the burned and unburned gas in a burned and an unburned gas zone. The mass and heat transfer rates between each zone were controlled by the heat release rate calculated by the TPA method. The difference between total energy delivered by the fuel and 
the energy required during the simulated combustion process (so called lower heating value multiplier parameter LHV $_{\text {multiplier }}$ ) was automatically compared by the software during the analysis. The software maximum absolute acceptable value of LHV $\mathrm{multiplier}$ should be less than $5 \%$, otherwise the simulation fails. The instantaneous in-cylinder and intake plenum pressure data used in the simulation were taken from the average of 100 consecutive cycles for each crank angle.

The time step was automatically set by the software obeying the Courant condition. Figure 3 presents the 1D engine model layout on the GT-Suite ${ }^{\circledR}$ environment. Valve controllers were used to input the unconventional NVO profile. A PID controller was applied to the direct injector in order to maintain a stoichiometric air/fuel ratio in the exhaust manifold, as measured in the experiment.

\subsection{Validation of the 1D engine model}

The model validation was performed by comparing the air mass and fuel mass flow rates, IMEP, lambda, and in-cylinder pressure through the whole cycle. As the exhaust air-fuel ratio at the exhaust pipe was imposed using a PID controller, the maximum difference between the experimental and simulated lambda was lower than $0.5 \%$. An LHV multiplier was a software parameter used to scale the fuel energy during the pressure analysis so that the target cumulative burn fraction was achieved. This essentially compensated for all cumulative errors and inaccuracies in measurement and model input to provide the most accurate burn rate possible. Comparisons between experimental and modelled in-cylinder pressure data of several distinct test points of different fuels and valve strategies are depicted in Figure 4. The comparison between modelled and simulated low pressure phase (pumping loop) data showed good pressure behaviour agreement, which means that the gas exchange is well characterized. Additionally, there's perfect agreement on the high pressure phase due to the use of TPA methodology. The differences between simulated and measured parameters as well as the calculated RGF are shown in Table 2. 


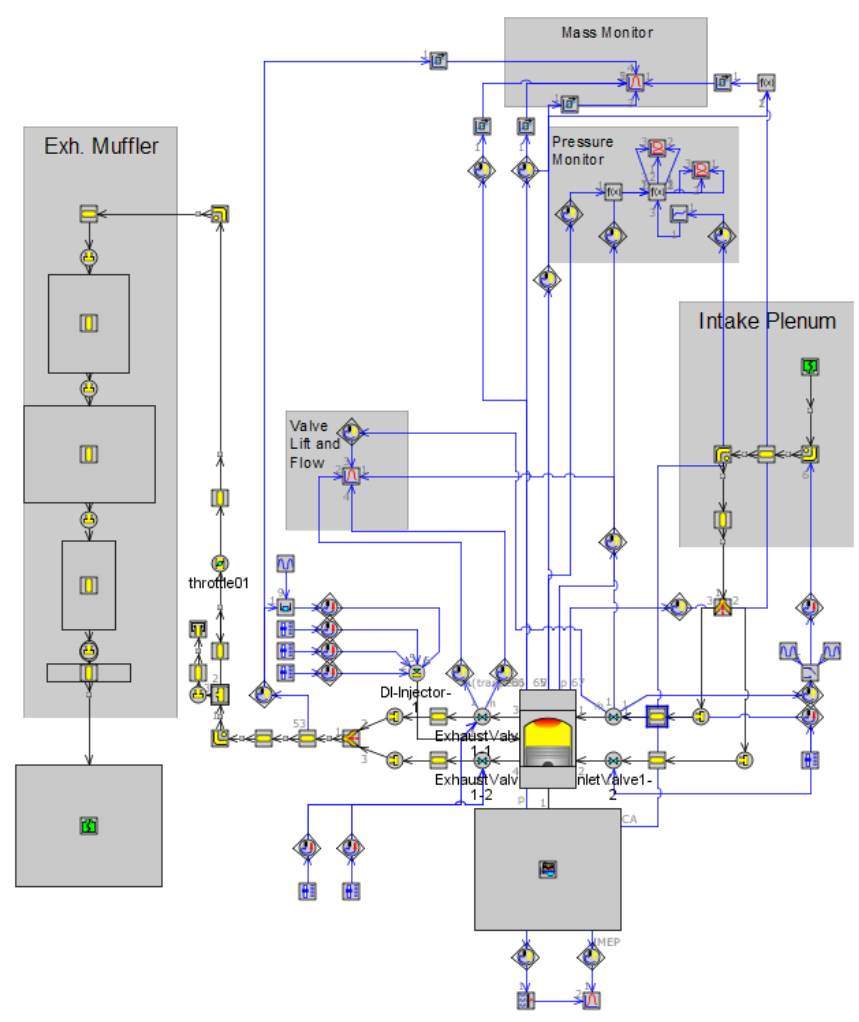

Figure 3. 1D camless engine model

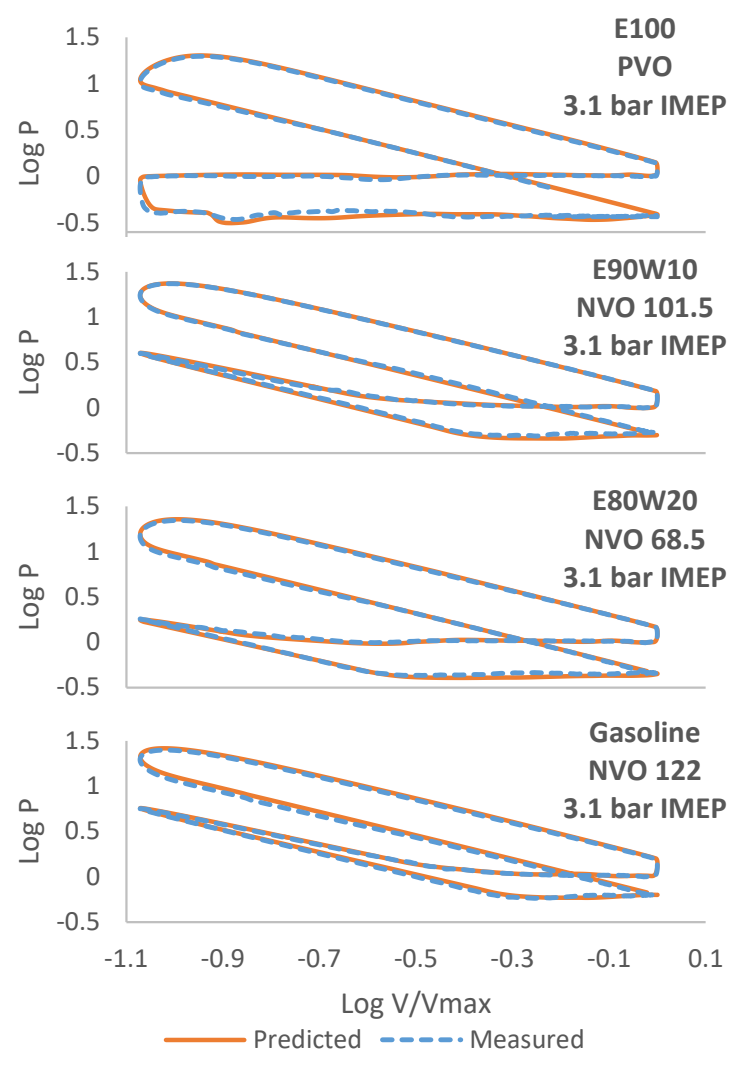

Figure 4. Modelled and experimental in-cylinder pressure comparison for different fuels and valve strategies. 
Table 2. 1D engine model validation: the difference between the engine model and the experimental results.

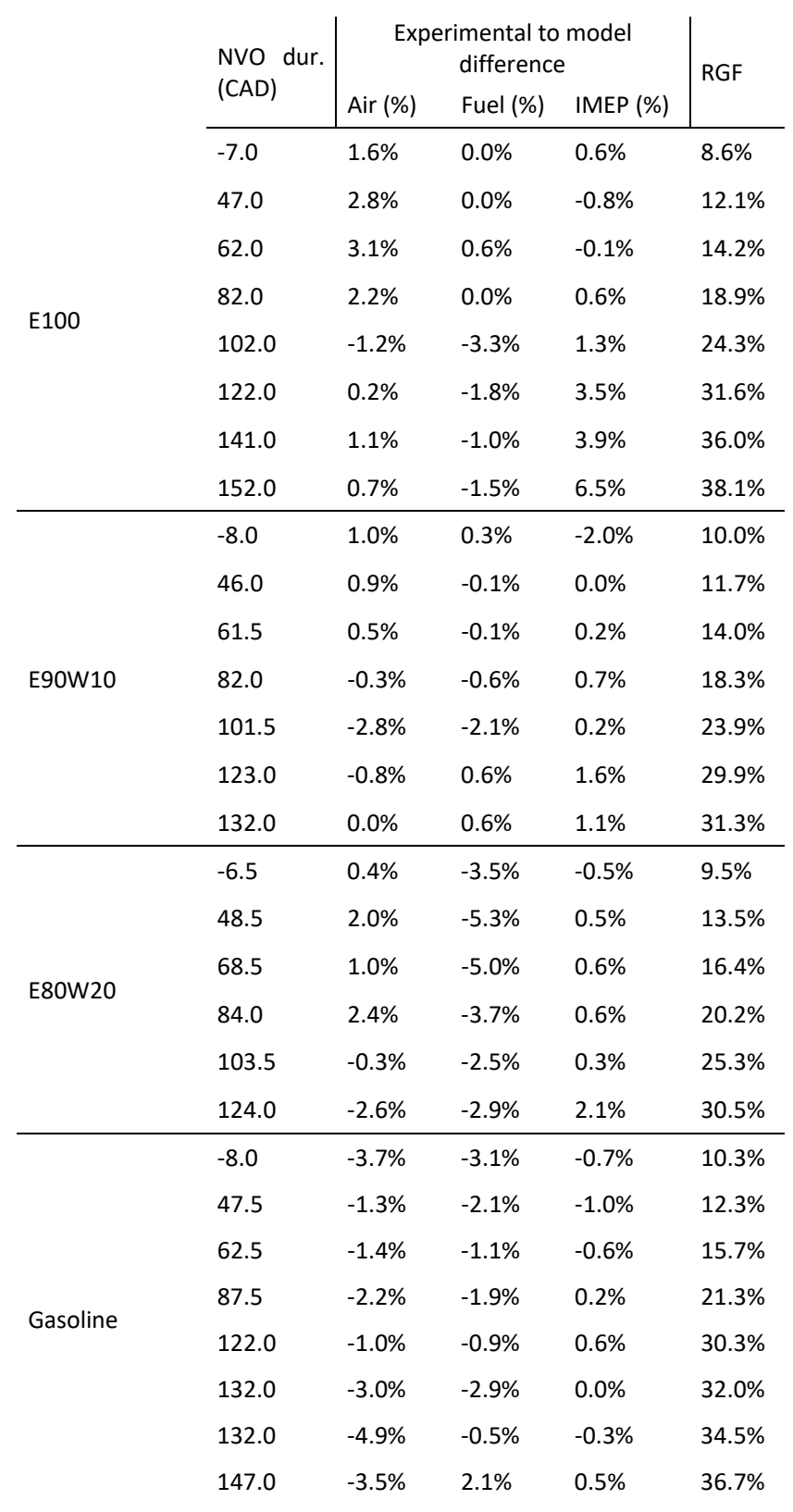

\section{Results}

\subsection{The effects of RGF on engine control and gas exchange efficiency}

Figure 5 presents the gas exchange parameters at different residual gas fractions and fuels. Considering a polytrophic compression process and a given intake pressure [56], [57] , the use of a constant intake valve closing (IVC) resulted in an effective compression ratio of 10.8. In addition, the fixed exhaust valve opening (EVO) yielded the same effective expansion ratio for all cases. In this way, the pumping mean effective pressure (calculated for the period between EVO and IVC) was a direct result of the throttle restriction used to reach the desired load at the considered MBT. Thus, an increase in the RGF through longer NVO 
periods effectively increased the PMEP, as higher intake pressures were required to maintain a stoichiometric engine operation at 3.1 bar IMEP as shown in Figure 5.

At a given RGF, differences between the required intake pressure for different fuels occurred due to changes in the stoichiometric air/fuel ratio. The increase on the required intake pressure when elevating the water content in ethanol was a result of a higher air mass necessary to keep the load constant. This was an indicative of a relatively lower net indicated efficiency for higher water content fuels (see Section 5.4).

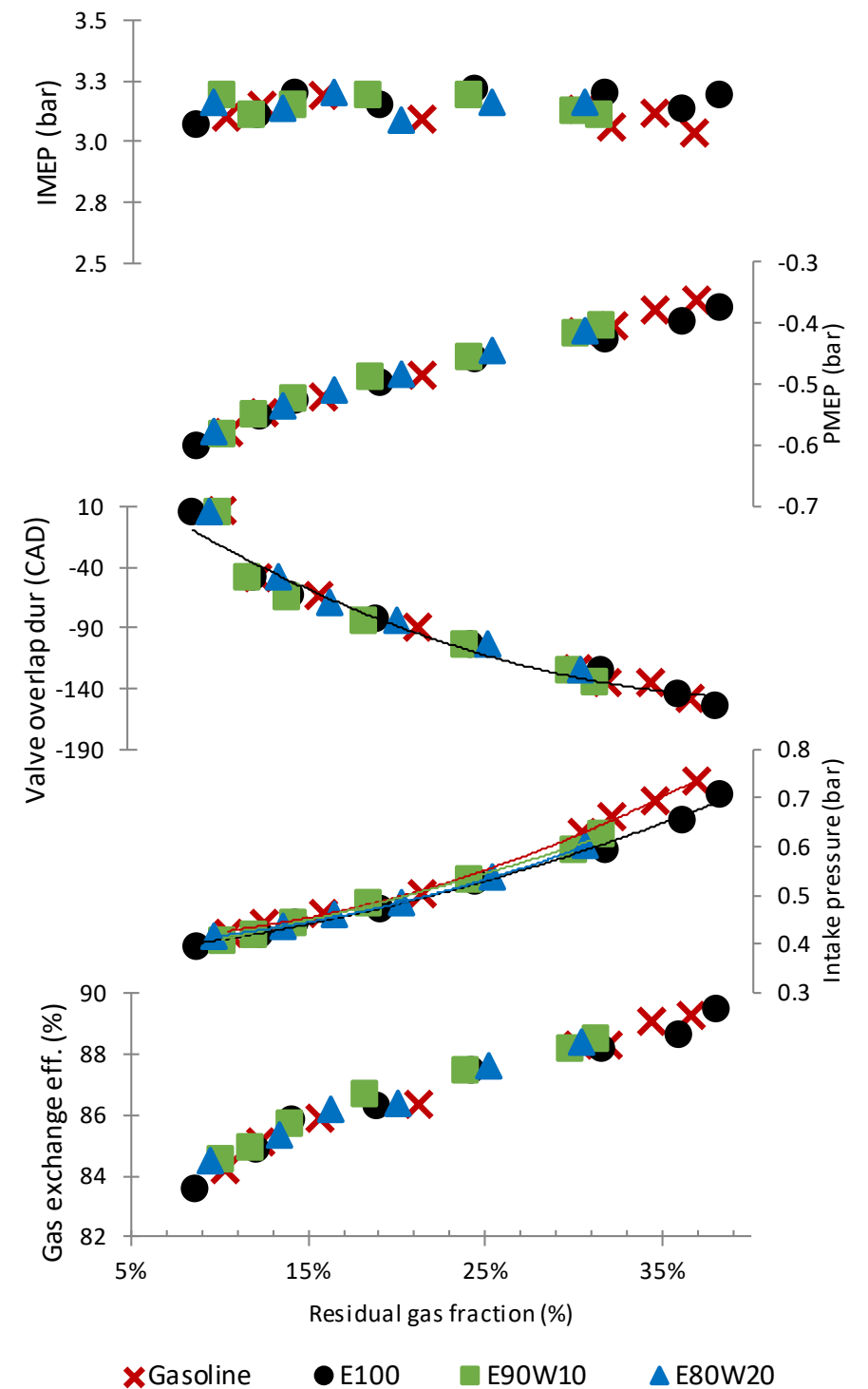

Figure 5. The effects of RGF on engine control and gas exchange efficiency. 


\subsection{The effects of RGF on combustion characteristics}

Figure 6 presents the effect of RGF on stoichiometric SI combustion of different fuels. The RGF varied from $8.5 \%$ to $10.5 \%$ for the positive valve overlap testing points. Any increase on water-in-ethanol content tended to increase the RGF content for a specific overlap duration. The increase on the NVO duration resulted in higher RGF trapping whilst diluting the charge mixture. The minimum spark timing for the best torque (MBT) had to be advanced as the RGF increased at longer NVO periods to maintain the optimum combustion phasing. The increase in water-in-ethanol content also required more advanced spark timings to achieve the MBT. Stable engine operation was attained with a RGF of up to $38 \%$ for E100. As the water-in-ethanol content was increased, the maximum acceptable RGF decreased due to unstable combustion as revealed by the relatively higher COV $_{\text {imep }}$ for E80W20.

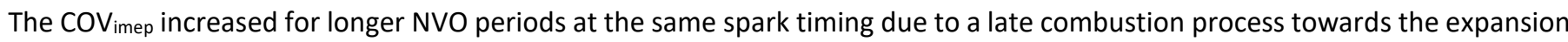
stroke. The combustion phase could be adjusted and the combustion cyclic variability reduced with more advanced spark timings. MBT was achieved in all cases. At the greatly diluted cases, spark timing reached approximately - 40 CAD ATDC and the flame development angle became so long that the $\mathrm{COV}_{\text {imep }}$ increased above $5 \%$ and further spark advance provided no benefit. As discussed in [58], the early flame stages during the FDA (flame development angle - period between the spark timing and the instant of $10 \%$ of mass fraction burned, CA10) are the most critical in terms of cyclic variability. In this way, it could be seen a

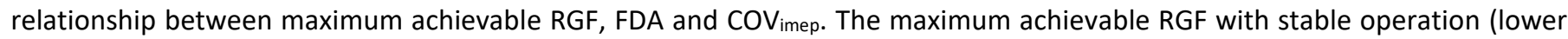
than $5 \% \mathrm{COV}_{\text {imep }}$ ) was achievable for a maximum FDA duration around 25 CAD. At this particular load, higher FDA values resulted on misfire and increased $\mathrm{COV}_{\text {imep }}$ above $5 \%$.

In general, a higher RGF increased the FDA duration, as well as the main combustion duration phase (given by the CA10-CA90 period). This increase occurred due to the dilution and higher heat capacity effects of water and $\mathrm{CO}_{2}$ in the residual gas. Consequently, there were reductions in the in-cylinder gas temperatures and the resulting exhaust gas temperature, as depicted in Figure 6.

As the RGF reached $30 \%$, the combustion duration started to level off and even decrease in some cases (e.g. E100 and gasoline). This could be attributed to the presence of flame quenching or, more likely, partial burn with excessive dilution by residual gas. This was supported by the higher THC emissions (see Figure 10). Actually, if less fuel was burned, combustion took less time to occur and its duration decreased. 


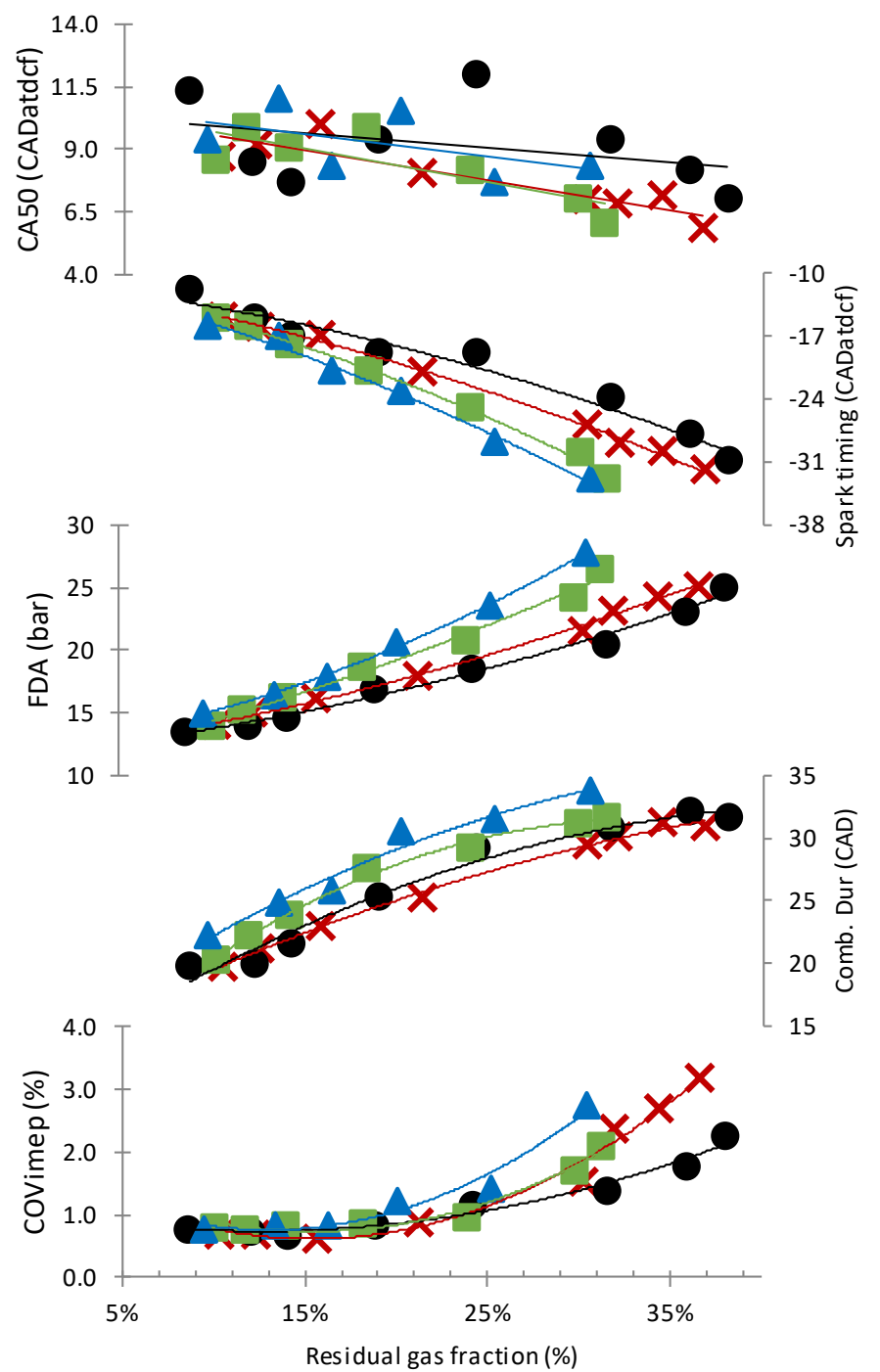

XGasoline $\bullet$ E100 E90W10 $\triangle$ E80W20

Figure 6. The effects of RGF on combustion characteristics. 


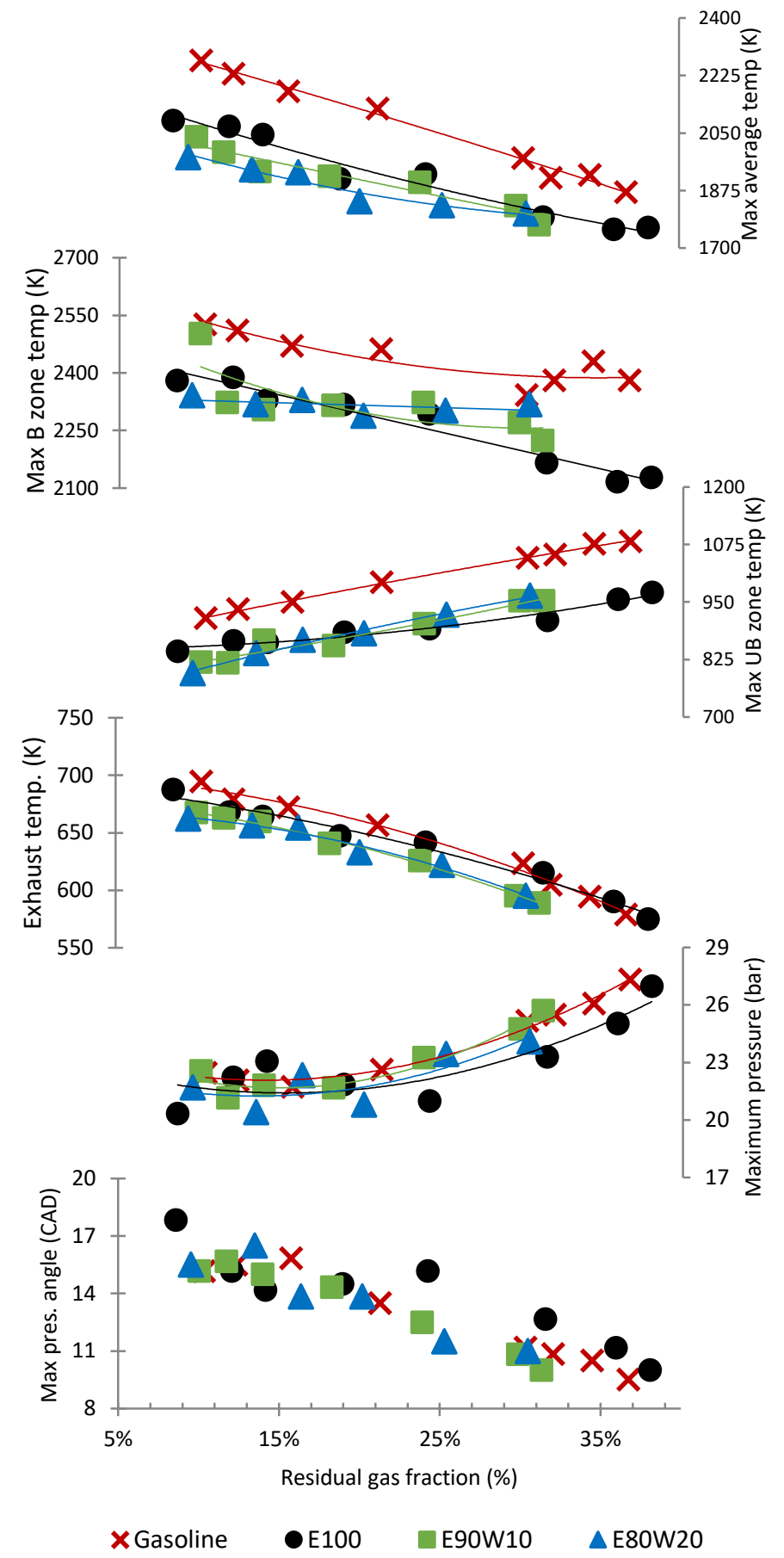

Figure 7. The effect of RGF on temperatures and pressures during and after the combustion event ( $B$ and UB stands for burned and unburned zones, respectively).

Water in ethanol acted as an additional diluent, slowing the combustion process and absorbing the combustion generated heat. This is supported by the lower burned gas peak temperature in Figure 7. Wet ethanol cases with high RGF required earlier spark timings to advance the angle of maximum pressure towards TDC. This resulted in higher maximum temperatures in the burned and unburned zones than those for E100. Nevertheless, the peak mean in-cylinder gas temperature turned out to be higher for E100, as demonstrated in Figure 8. 

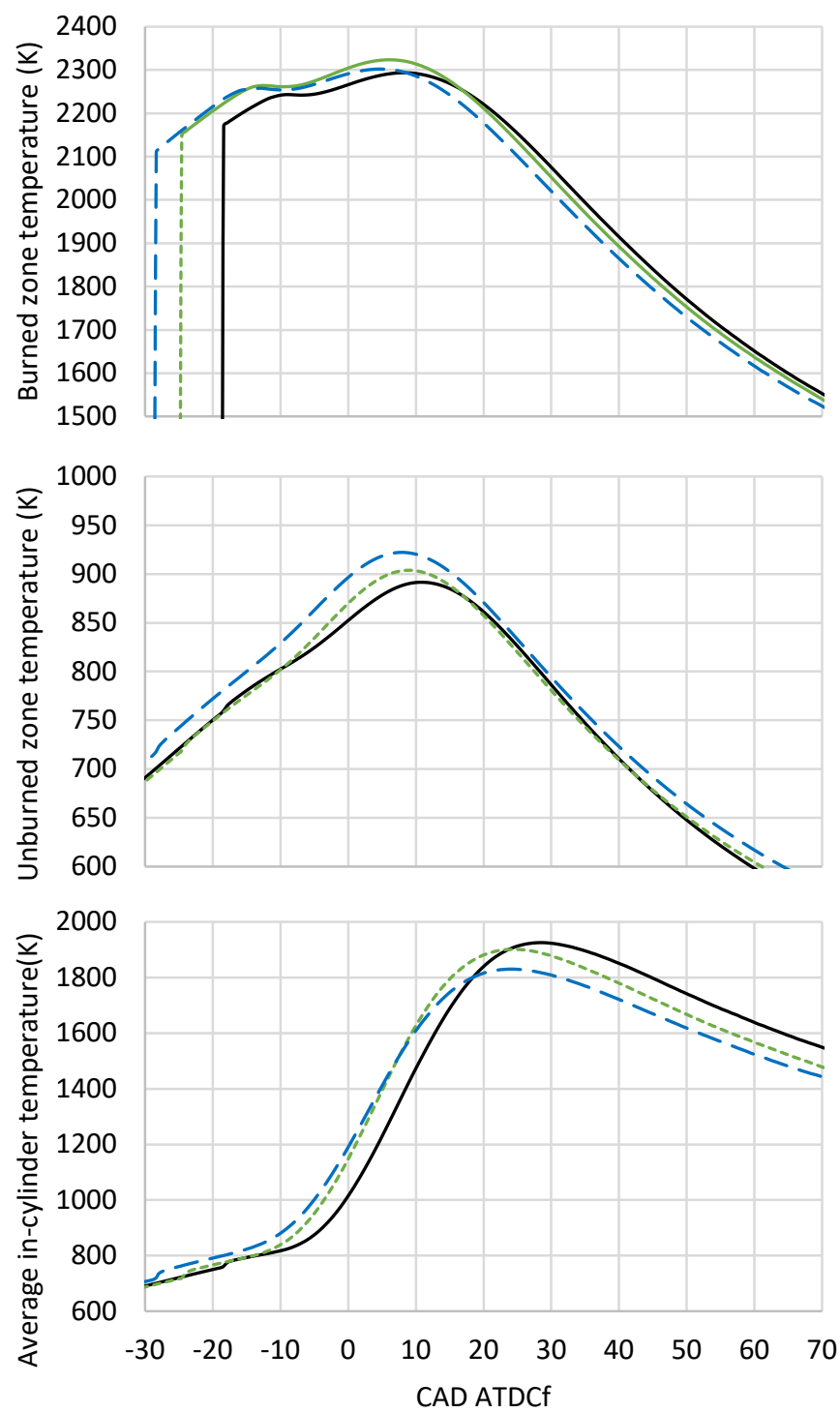

- E100 --.--- E90W10 - - E80W20

Figure 8. The effect of water-in-ethanol content on in-cylinder gas temperatures for an engine operation with a RGF of approximately $25 \%$.

E80W20 was the least tolerant fuel to RGF due to its higher water fraction. As the water-in-ethanol content was reduced, higher residual gas dilution could be added until the in-cylinder charge temperature decreased to levels that stable flame propagation could not be sustained. This unstable condition occurred when the peak mean in-cylinder gas temperature was less than $1750 \mathrm{~K}$. These results are supported by articles reporting that similar in-cylinder temperature trends at TDC resulted in unstable combustion in lean burn gasoline engines [59] and that further increase in hot RGF was not able to promote autoignition as the end-gas could not reach more than $950 \mathrm{~K}$ for the ethanol fuels or $1100 \mathrm{~K}$ for gasoline [57] . At highly diluted conditions (e.g. RGF $>25 \%)$, the exhaust gas temperatures remained above $650 \mathrm{~K}$. It has been shown that a three-way catalyst would be a cost 
effective solution to manage the majority of wet ethanol emissions [12]. However, the efficiency of the after-treatment device would be impaired at exhaust gas temperatures of less than $650 \mathrm{~K}$.

Figure 9 shows the effect of RGF on heat release rate (HRR) of an engine operation with E100 and E80W20. The highest heat release rate and shortest combustion occurred with conventional valve timing without NVO, with approximately $10 \%$ RGF. The combustion process became slower and the peak in heat release was reduced as the RGF trapped through NVO increased. However, the maximum pressure increased considerably due to higher in-cylinder mass as shown in Figure 7 . The higher waterin-ethanol content reduced the heat release peak and lengthened the combustion duration. The point of $50 \%$ of mass fraction burned (CA50) and the maximum pressure angle ( $\left.C A_{m p}\right)$ moved towards TDC at more diluted charges and higher water-in-ethanol content fuels. Lower in-cylinder heat losses attributed to lower in-cylinder temperatures during combustion is one of the reasons for angle of maximum pressure closer to TDC [60].

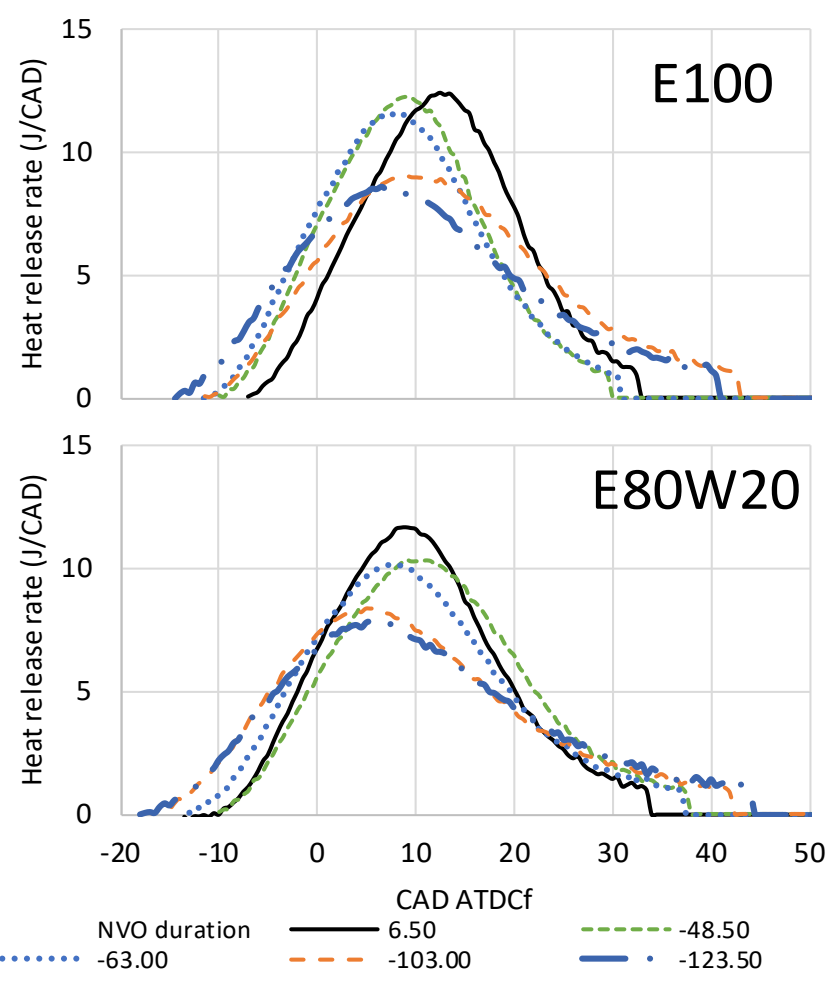

Figure 9. The effect of RGF on heat release rate of E100 and E80W20 engine operation.

\subsection{The effects of RGF on engine-out emissions}

Figure 10 shows the specific emissions of $\mathrm{CO}, \mathrm{THC}$, and NOx. Poor fuel vaporisation and impingement during the direct injection was a concern while increasing the water-in-ethanol content. As discussed in the previous work performed in the same engine 
[61], the fuel spray impinged upon the piston and decreased the combustion efficiency when injecting near gas exchange TDC. Alternatively, the mixing formation was impaired and the cooling effect reduced when fuel was injected during the compression stroke. Therefore, the fuel injection timing for the PVO strategy (e.g. condition with the lowest RGF) was set to the beginning of the intake stroke at 32 CAD ATDC. This provided the optimum trade-off between charge cooling, fuel spray impingement, and in-cylinder charge homogeneity.

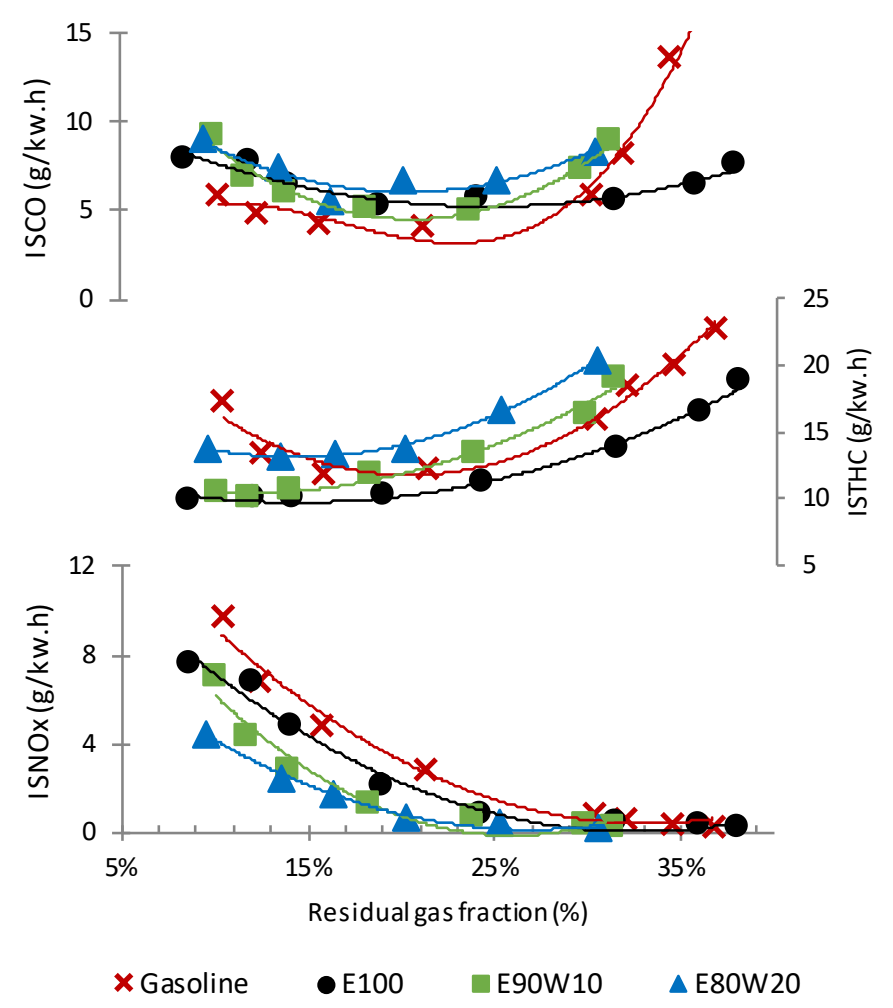

Figure 10. The effects of RGF on engine-out emissions.

In the NVO cases, the fuel injection in a high temperature environment during the recompression of the residual gases was selected to achieve better fuel vaporization and combustion efficiency. The charge homogeneity was also improved due to the longer time available for charge mixing process. The higher air to fuel mixture inhomogeneity during the operation with overlap (PVO) was emphasized by the higher CO emissions than that of NVO operation with higher RGFs, Figure 10 as CO was primarily formed in the fuel rich mixture. When the RGF was further increased, CO emissions rose slightly due to lower in-cylinder

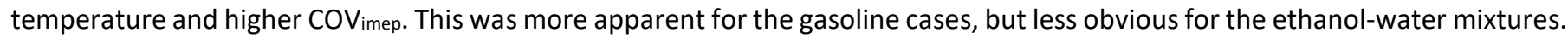
Even though, $\mathrm{CO}$ emissions for higher water content ethanol seemed to be slightly lower than that of anhydrous ethanol which presented higher combustion temperatures. 
The presence of water in ethanol increased THC emissions at a given RGF. The presence of water and other diluents reduced the fuel laminar flame speed [62]-[64] and turbulent flame wrinkling during SI combustion [14]. These effects contributed to slowing down the combustion process and lowering the in-cylinder gas temperatures, which deteriorated THC emissions for higher water-in-ethanol content and higher RGF.

For gasoline, the lowest THC emissions occurred at an intermediate NVO with RGF between $15 \%$ and $25 \%$. In these cases, the recompression temperatures probably enabled some level of fuel reforming, while the mean in-cylinder gas temperature during combustion was high enough to complete the THC oxidation process. As shown in a previous study [27], the reforming process transforms the fuel molecules into smaller and highly active radicals which can facilitate the oxidation reactions during combustion. Similar THC emission behaviour occurred for E80W20, where the increased water content may had contributed to the ethanol reforming process. On the other hand, the increase in RGF only increased THC emissions for E100 and E90W10.

Another benefit of NVO when compared to a conventional valve strategy (e.g. PVO) was the lower NOx emissions. According to the Zeldovich mechanism [65], most NOx was formed in the burned gas region due to high temperature in the presence of sufficient oxygen. A smaller percentage of NOx could be also produced in stoichiometric-to-rich flame regions due to chemical interaction between the hydrocarbon and nitrogen according to the Prompt NO formation mechanism. As a result, the NOx formation in the burned gas region was significantly reduced by the higher dilution and lower combustion temperatures introduced by RGF.

Anhydrous ethanol combustion reduced NOx emissions by approximately $50 \%$ when compared to a gasoline SI operation. The water cooling effect of wet ethanol further reduced NOx emissions. NOx emissions of less than $1 \mathrm{~g} / \mathrm{kWh}$ were obtained when using a RGF of approximately $25 \%$. This is a very low value and a significant achievement for a stoichiometric $\mathrm{SI}$ combustion at 3.1 bar IMEP. The lowest ISNOx of $0.23 \mathrm{~g} / \mathrm{kWh}$ was attained by an E80W20 stoichiometric operation at a RGF of $31 \%$, which is comparable to NOx levels produced by CAI combustion [66].

\subsection{The effects of RGF on engine performance}

The effects of RGF were further analysed with regard to the combustion efficiency, thermodynamic efficiency, gas exchange efficiency, and net indicated efficiency are showed in Figure 11. As previously stated, the results for the PVO operation are represented by a RGF of approximately $10 \%$. The remaining test results were obtained during the NVO operation.

The combustion efficiency remained relatively similar for the water-in-ethanol mixtures when using a PVO strategy. This was possibly a result of the high combustion temperatures obtained with low RGF. The increase in RGF via NVO initially allowed for 
slightly higher combustion efficiencies. This was attributed to a better charge mixing process and the lower CO and THC emissions, as previously discussed. As the RGF increased beyond 18\%, combustion efficiency decreased because of the production of higher THC emissions. There was a visible decrease in combustion efficiency with the increase in water content for all NVO cases. This was associated with the dilution effect and the lower mean in-cylinder gas temperatures.

The intake pressure for a stoichiometric PVO operation was lower than that required with the NVO strategy. This led to relatively higher throttling losses that increased the pumping work and decreased the gas exchange efficiency. When NVO strategy was used, the recompressed residuals increased the in-cylinder temperature during the intake stroke requiring higher intake pressure to induce fresh air. This fact decreased the pumping work and increased the gas exchange efficiency gradually as more residual gas was trapped due to higher NVO periods. There was a slight increase in gas exchange efficiency at higher water-in-ethanol contents.

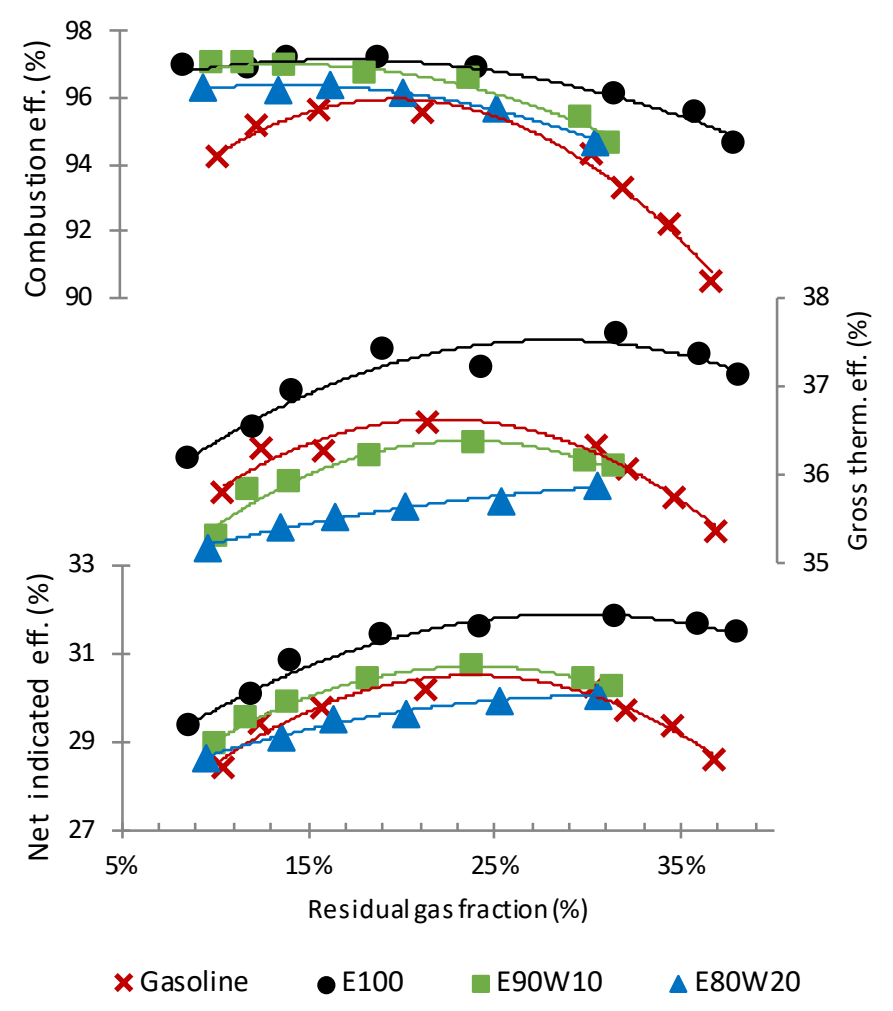

Figure 11. The effects of RGF on engine performance.

Since MBT was achieved for all operating conditions, the combustion phasing was optimised for the best possible thermodynamic efficiency at each operating condition. By comparing the thermodynamic efficiency between E100 and gasoline, it could be pointed out that the higher combustion temperatures of the gasoline cases potentially increased the energy fraction lost to heat transfer and in the exhaust gases. The reduction in thermodynamic efficiency for ethanol fuels with higher water content was attributed to an increase in the compression work and exhaust losses. This was caused by the longer combustion duration for 
E90W10 and E80W20. Additionally, the higher heat capacity of the exhaust gases due to increased water vapour content also increased the energy lost.

E100 achieved the best results in terms of net indicated efficiency, which combines the effects of gas exchange efficiency, combustion efficiency, and thermodynamic efficiency. Alternatively, E90W10 yielded $1.8 \%$ higher net indicated efficiency, on average, than a gasoline engine operation. Wet ethanol with $20 \%$ of water typically attained the lowest levels of net indicated efficiency at a given RGF. The use of NVO, however, played an important role in maximising the net indicated efficiency via a higher gas exchange efficiency (see Figure 5). This trend held true until lower combustion efficiencies and/or higher $\mathrm{COV}_{\text {imep }}$ adversely affected the performance of cases with high RGF.

This study also demonstrated that the optimum RGF, and thus NVO period, was the main cause for indicated efficiency differences between different fuels seen as gross thermodynamic efficiencies. After that, combustion efficiency played a more important role while gas exchange efficiency had minor influence on reducing the indicated efficiency of wet ethanol cases compared to anhydrous ethanol cases. It should also be pointed out that the maximum net indicated efficiency varied slightly on the fuel used. A potential solution for a commercial flex-fuel engine is to use a NVO period that introduces a RGF of $25 \%$ at a part load condition. This strategy allows for an excellent compromise between performance, emissions, and engine calibration complexity.

\section{Conclusions}

A single cylinder direct injection SI engine equipped with a fully variable valve actuation system was used to evaluate the influence of the residual gas fraction at a typical part load condition of 3.1 bar and $1500 \mathrm{rpm}$. The engine was operated with anhydrous ethanol (E100), two wet ethanol mixtures (E90W10 and E80W20), and RON 95 gasoline. The effects of alcohol fuel and water-in-ethanol content on combustion characteristics, emissions, and performance were investigated. Internal exhaust gas recirculation was achieved through a positive valve overlap (PVO) while residual gas trapping was attained via a negative valve overlap (NVO) strategy. The residual gas fraction (RGF) varied from $10 \%$ (PVO) up to $38 \%$ (NVO). The primary findings could be summarized as follows:

1. The presence of water increased the flame development and propagation periods. The impact of water (v/v) content in wet ethanol became more significant with increased RGF. MBT could be achieved at all tested cases through spark timing advance to compensate for changes in the combustion process. As the water content increased to $20 \%$, optimum combustion phasing was only achieved when operating with lower residual gas concentrations than those used with E100 and gasoline. Misfire 
occurred and impaired the engine operation when more advanced spark timings could not achieve a flame development angle of less than 25 CAD.

2. The increase in the RGF tended to increase the maximum in-cylinder pressure as the centre of combustion had to be advanced and the angle of maximum pressure occurred closer to TDC. Nevertheless, lower mean in-cylinder gas temperatures were attained due to higher charge heat capacity.

3. The better charge mixing process of the NVO strategy led to higher combustion efficiency as supported by the lower CO and THC emissions. These emissions were comparable to the levels found in the literature for conventional SI throttled operation at the same load. The improved charged homogeneity and lower temperature achieved with NVO resulted in low NOx emissions, similar to that found in CAl operation at the same load while maintaining the advantage of combustion phasing control through spark timing.

4. The fuel injection at the beginning of the NVO recompression period enabled better mixing and enhanced combustion efficiency relative to conventional PVO operation. As the cylinder temperature rose during the intake phase due to the hot trapped recompressed gases, less throttling was required, reducing the pumping loses and hence increasing gas exchange efficiency. These effects combined resulted in maximum increase in engine indicated efficiency of $8.6 \%, 6.1 \%, 4.9 \%$ and $6.4 \%$ for E100, E90W10, E80W20 and gasoline, respectively.

Overall, it was found that the presence of water decreased the indicated efficiency when the engine was operated with a positive valve overlap at a typical part load condition. Nonetheless, the negative valve overlap strategy enabled stable wet ethanol engine operation and higher net indicated efficiencies than those attained with a positive valve overlap. These improvements were associated with the better mixture preparation, lower pumping losses, and higher gross thermodynamic efficiency achieved with residual gas trapping. Thus, the use of the NVO valve strategy on passenger car engines would be enabled by the new and more affordable FVVA technologies, and this can be another alternative to help on achieving the near future emission legislation limits.

\section{Acknowledgements}

The authors would like to acknowledge the Brazilian Council for Scientific and Technological Development (CNPq - Brazil) for supporting the PhD studies of Dr Lanzanova and Dr Dalla Nora, as well as CAPES Foundation (Brazil) for supporting the PhD study of Dr Pedrozo at Brunel University London under the supervision of Prof. Hua Zhao. Dr Lanzanova also would like to acknowledge CNPq - Brazil for supporting his current post-doctoral activities at the Federal University of Santa Maria (Brazil). 


\section{Nomenclature}

CAD - Crank angle degree; CAI - Controlled autoignition; $\mathrm{CO}$ - Carbon monoxide; $\mathrm{CO}_{2}$ - Carbon dioxide; $\mathrm{COV}_{\mathrm{imep}}$ - Covariance of IMEP; CPS - Cam profile switch; CVVL - Continuously variable valve lift; DI - Direct fuel injection; $e$-ethanol volumetric content on fuel; EGR - Exhaust gas recirculation; EIVC - Early intake valve closure; EVC - Exhaust valve closure; EVO - Exhaust valve opening; ExxWyy - Mixture of xx\% of ethanol in yy\% of water; FDA - Flame development angle; FID - Flame ionization detector; FVVA - Fully variable valve actuation; GHG - Greenhouse gases; HC - Hydrocarbon; HCCl - Homogeneous charge compression ignitions; HRR - Heat release rate; iEGR - Internal exhaust gas recycling; IMEP - Indicated mean effective pressure; ISCO - indicated specific CO emissions; ISNOx - Indicated specific NOx emissions; ISTHC - Indicated specific THC emissions; IVC - Intake valve closure; IVO - Intake valve opening; $k_{f i d}$ - FID correction factor; $k_{w}$ - dry-to-wet emissions correction factor; LHV - lower heating value; MBT - Minimum spark advance for maximum brake torque; NOx - Nitrogen oxides; NVO - Negative valve overlap; $p$ Pressure; PI - Indicated power; PFI - Port fuel injection; PMEP - Pumping mean effective pressure; PVO - Positive valve overlap; $Q_{\text {net }}$ - Apparent heat release rate; RCCI - Reactive controlled compression ignition; RG - Residual gas; RGF - Residual gas fraction; RON - Research octane number; SACI - Spark assisted compression ignition; SI - Spark ignition; TDC - Top dead centre; THC Total hydrocarbon; THC - Total hydrocarbons; $u_{i}$ - raw gas exhaust factor of "i"; $\mathrm{V}$ - Instantaneous in-cylinder volume; v/v Volume/volume; VVA - Variable valve actuation; Wc - Work per cycle; $x_{i}$ - concentration of "i" gas; $\dot{m}_{l}$ - Mass flow rate of "i”; $\nu$ Ratio of specific heats; $\eta_{g e}$ - Gas Exchange efficiency; $\eta_{c}$ - Combustion efficiency; $\eta_{i}$ - Net indicated efficiency; $\eta_{t h}$ - Thermodynamic efficiency.

\section{References}

[1] European Commission, “EU Transport in Figures," 2014.

[2] US EPA, “DRAFT Inventory of U . S . Greenhouse Gas Emissions and Sinks : 1990 - 1998,” 2016.

[3] M. R. Ladisch and K. Dyck, “Dehydration of ethanol: new approach gives positive energy balance.," Science, vol. 205, no. 4409, pp. 898-900, Aug. 1979.

[4] D. L. Flowers, S. M. Aceves, and J. M. Frias, “Improving Ethanol Life Cycle Energy Efficiency by Direct Utilization of Wet Ethanol in HCCl Engines," in SAE Technical Paper, 2007, no. 2007-01-1867, pp. 1070-1078.

[5] E. L. López-Plaza et al., "Experimental and Theoretical Study of the Energy Savings from Wet Ethanol Production and Utilization," Energy Technol., vol. 2, no. 5, pp. 440-445, May 2014.

[6] H. a Saffy, W. F. Northrop, D. B. Kittelson, and A. M. Boies, "Energy, carbon dioxide and water use implications of hydrous 
ethanol production," Energy Convers. Manag., vol. 105, pp. 900-907, 2015.

[7] D. Cordon, E. Clarke, S. Beyerlein, J. Steciak, and M. Cherry, "Catalytic Igniter to Support Combustion of EthanolWater/Air Mixtures in Internal Combustion Engines," SAE Tech. Pap., no. 2002-01-2863, 2002.

[8] J. Olberding, D. C. S. Beyerlein, J. Steciak, and M. Cherry, “Dynamometer Testing of an Ethanol-Water Fueled Transit Van," in SAE Technical Paper, 2005, no. 2005-01-3706.

[9] M. Martins, T. Lanzanova, and R. Sari, “Low Cost Wet Ethanol for Spark-Ignited Engines: Further Investigations," SAE Int. J. Fuels Lubr., vol. 8, no. 2015-01-0954, Apr. 2015.

[10] T. D. M. Lanzanova, M. Dalla Nora, and H. Zhao, “Performance and economic analysis of a direct injection spark ignition engine fueled with wet ethanol," Appl. Energy, vol. 169, pp. 230-239, May 2016.

[11] R. Munsin, Y. Laoonual, S. Bavornsethanan, and S. Jugjai, “An Experimental Study on Aldehyde Emissions of a Hydrous Ethanol Fuelled Small SI Engine Generator Set," in The First TSME International Conference on Mechanical Engineering, 2010, p. 8.

[12] R. Munsin, Y. Laoonual, S. Jugjai, and Y. Imai, “An experimental study on performance and emissions of a small SI engine generator set fuelled by hydrous ethanol with high water contents up to 40\%," Fuel, vol. 106, pp. 586-592, Apr. 2013.

[13] S. Brewster, D. Railton, M. Maisey, and R. Frew, "The effect of E100 water content on high load performance of a spray guide direct injection boosted engine," SAE Tech. Pap., no. 2007-01-2648, 2007.

[14] A. Augoye and P. Aleiferis, "Characterization of Flame Development with Hydrous and Anhydrous Ethanol Fuels in a Spark-Ignition Engine with Direct Injection and Port Injection Systems," SAE Tech. Pap., no. 2015-09-02, Oct. 2014.

[15] M. M. Koupaie, A. Cairns, H. Vafamehr, and T. D. M. Lanzanova, “A study of hydrous ethanol combustion in an optical central direct injection spark ignition engine," Appl. Energy, vol. 237, no. January, pp. 258-269, 2019.

[16] A. Megaritis, D. Yap, and M. L. Wyszynski, “Effect of water blending on bioethanol HCCl combustion with forced induction and residual gas trapping," Energy, vol. 32, no. 12, pp. 2396-2400, Dec. 2007.

[17] A. Megaritis, D. Yap, and M. L. Wyszynski, "Effect of inlet valve timing and water blending on bioethanol HCCl combustion using forced induction and residual gas trapping," Fuel, vol. 87, no. 6, pp. 732-739, May 2008.

[18] J. H. Mack, S. M. Aceves, and R. W. Dibble, "Demonstrating direct use of wet ethanol in a homogeneous charge compression ignition (HCCl) engine," Energy, vol. 34, no. 6, pp. 782-787, Jun. 2009.

[19] S. Saxena, S. Schneider, S. Aceves, and R. Dibble, "Wet ethanol in $\mathrm{HCCl}$ engines with exhaust heat recovery to improve the energy balance of ethanol fuels," Appl. Energy, vol. 98, pp. 448-457, Oct. 2012.

[20] S. Saxena, D. Vuilleumier, D. Kozarac, M. Krieck, R. Dibble, and S. Aceves, “Optimal operating conditions for wet ethanol 
in a $\mathrm{HCCl}$ engine using exhaust gas heat recovery," Appl. Energy, vol. 116, pp. 269-277, Mar. 2014.

[21] A. B. Dempsey, B. Das Adhikary, S. Viswanathan, and R. D. Reitz, "Reactivity Controlled Compression Ignition Using Premixed Hydrated Ethanol and Direct Injection Diesel," in Proc. ASME. 44427; ASME 2011 Internal Combustion Engine Division Fall Technical Conference, 2012, vol. 134, no. August 2012, pp. 963-975.

[22] W. Fang, D. B. Kittelson, and W. F. Northrop, “An Experimental Investigation of Reactivity-Controlled Compression Ignition Combustion in a Single-Cylinder Diesel Engine Using Hydrous Ethanol," Proc. ASME 2013 Intern. Combust. Engine Div. Fall Tech. Conf., vol. 137, no. May, pp. 1-9, 2013.

[23] Nikkei, “Mazda's new engine boosts fuel efficiency by 30\%," 2017. [Online]. Available: http://asia.nikkei.com/Business/Companies/Mazda-s-new-engine-boosts-fuel-efficiency-by-30. [Accessed: 20-Jan2017].

[24] T. D. M. Lanzanova et al., "Performance Analysis of a Spark Ignited Engine Running on Different Water-in-Ethanol Mixtures," in SAE Technical Paper, 2013.

[25] T. Urushihara, K. Hiraya, A. Kakuhou, and T. Itoh, "Expansion of HCCl operating region by the combination of direct fuel injection, negative valve overlap and internal fuel reformation," SAE Tech. Pap., no. 10.4271/2003-01-0749, 2003.

[26] G. Gnanam, M. Johnson, A. Sobiesiak, and G. Reader, “HCCl Combustion With Internal Fuel Reforming, Varied Levels of EGR and Charge Preheat - A Computational Study," SAE Tech. Pap., no. 2005-01-0140, 2005.

[27] M. Tongroon and H. Zhao, "Analysis of the effect of direct injection of alcohol fuel on minor heat release reactions and controlled autoignition combustion," Proc. Inst. Mech. Eng. Part D J. Automob. Eng., vol. 226, no. 12, pp. 1678-1688, May 2012.

[28] K. Hatano, K. Lida, H. Higashi, and S. Murata, “Development of a New Multi-Mode Variable Valve Timing Engine," SAE Tech. Pap., no. 930878, 1993.

[29] M. Hakariya, T. Toda, and M. Sakai, “The New Toyota Inline 4-cylinder 2.5L Gasoline Engine," SAE Tech. Pap., no. 201701-1021, 2017.

[30] M. Shibata et al., "New 1.0L I3 Turbocharged Gasoline Direct Injection Engine," SAE Tech. Pap., no. 2017-01-1029, Mar. 2017.

[31] R. Flierl and M. Kluting, "The Third Generation of Valvetrains - New Fully Variable Valvetrains for Throttle-Free Load Control," SAE Tech. Pap., no. 2000-01-1227, 2000.

[32] C. Luttermann, E. Schueenemann, and N. Klauer, "Enhanced VALVETRONIC technology for meeting SULEV emission requirements.," Soc. Automot. Eng. [Special Publ. SP, vol. SP-2025, no. Advanced Catalysts and Substrates 2006, pp. 7- 
$11,2006$.

[33] W. Gottschalk, U. Lezius, and L. Mathusall, "Investigations on the Potential of a Variable Miller Cycle for SI Knock Control," Apr. 2013.

[34] I. Trevas, C. Pimenta, H. Fernandes, M. Carvalho, and R. Montemor, "Combustion Analysis on a Variable Valve Actuation Spark Ignition Engine Operating With E22 and E100," SAE Tech. Pap., no. 2017-01-1069, 2017.

[35] T. Sugiyama, R. Hiyoshi, S. Takemura, and S. Aoyama, "Technology for Improving Engine Performance using Variable Mechanisms," SAE Tech. Pap., no. 2007-01-1290, 2007.

[36] A. Titolo, "The Variable Valve Timincl - System - Application on a V8 Engine," SAE Tech. Pap., no. $910009,2015$.

[37] J. W. G. Turner, M. D. Bassett, R. J. Pearson, G. Pitcher, and K. J. Douglas, “New Operating Strategies Afforded by Fully Variable Valve Trains," SAE Tech. Pap., no. 2004-01-1386, 2004.

[38] N. Milovanovic, D. Blundell, S. Gedge, and J. Turner, "Cam Profile Switching ( CPS ) and phasing strategy vs Fully Variable Valve Train ( FVVT ) strategy for transitions between spark ignition and controlled auto ignition modes," SAE Tech. Pap., no. 2005-01-0766, 2005.

[39] Freevalve, "Freevalve Technology," 2017. [Online]. Available: http://www.freevalve.com/. [Accessed: 18-Apr-2017].

[40] D. Shao, X. Sichuan, and A. Du, "Research on a New Electromagnetic Valve Actuator Based on Voice Coil Motor for Automobile Engines A New Design of Voice Coil Electromagnetic Valve," SAE Tech. Pap., no. 2017-01-1070, 2017.

[41] Y. Zhang and H. Zhao, "Investigation of combustion, performance and emission characteristics of 2-stroke and 4-stroke spark ignition and CAl/HCCl operations in a DI gasoline," Appl. Energy, vol. 130, pp. 244-255, Oct. 2014.

[42] M. Dalla Nora and H. Zhao, "High load performance and combustion analysis of a four-valve direct injection gasoline engine running in the two-stroke cycle," Appl. Energy, vol. 159, pp. 117-131, Dec. 2015.

[43] T. de Melo, M. de Brito, G. Machado, and C. Paiva, "Procedure for Uncertainty of Measurement Determination of Spark Ignition Engine Emission Tests," SAE Tech. Pap., no. 2012-36-0488, 2012.

[44] K. Kar, R. Tharp, M. Radovanovic, I. Dimou, and W. K. Cheng, “Organic gas emissions from a stoichiometric direct injection spark ignition engine operating on ethanol/gasoline blends," Int. J. Engine Res., vol. 11, no. 6, pp. 499-513, Dec. 2010.

[45] T. Wallner, "Correlation Between Speciated Hydrocarbon Emissions and Flame lonization Detector Response for Gasoline/Alcohol Blends," J. Eng. Gas Turbines Power, vol. 133, no. 8, p. 082801, 2011.

[46] Economic Commission for Europe of the United Nations, "Regulation No 49 of the Economic Commission for Europe of the United Nations (UN/ECE)," Off. J. Eur. Union, no. 171, pp. 1-390, 2013.

[47] M. Ojapah, H. Zhao, and Y. Zhang, "Effects of Ethanol on Part-Load Performance and Emissions Analysis of SI Combustion 
with EIVC and Throttled Operation and CAI Combustion," SAE Tech. Pap., no. 2014-01-1611, 2014.

[48] M. Ojapah, H. Zhao, and Y. Zhang, "Effects of Ethanol on Performance and Exhaust Emissions from a DI Spark Ignition Engine with Throttled and Unthrottled Operations," SAE Tech. Pap., no. 2014-01-1393, 2014.

[49] T. Lanzanova, H. Zhao, and M. Dalla Nora, "Advanced valve timing strategies for high efficiency SI operation with ethanol," in Engine Combustion Processes - Current Problems and Modern Techniques (XIIIth Congress), 2017, pp. 427437.

[50] S. Brewster, D. Railton, M. Maisey, and R. Frew, "The Effect of E100 Water Content on High Load Performance of a Spray Guide Direct Injection Boosted Engine," in SAE Technical Paper, 2007.

[51] J. B. Heywood, Internal Combustion Engine Fundamentals, 1st ed., vol. 21. McGraw-Hil, 1988.

[52] T. D. M. Lanzanova, "Experimental investigations of anhydrous and wet ethanol combustion in a spark ignition engine," Brunel University London, 2017.

[53] T. Lanzanova, M. D. Nora, and H. Zhao, "Investigation of Early and Late Intake Valve Closure Strategies for Load Control in a Spark Ignition Ethanol Engine," SAE Int. J. Engines, vol. 10, no. 3, 2017.

[54] V. B. Pedrozo, I. May, T. D. M. Lanzanova, and H. Zhao, "Potential of internal EGR and throttled operation for low load extension of ethanol-diesel dual-fuel reactivity controlled compression ignition combustion on a heavy-duty engine," Fuel, vol. 179, 2016.

[55] Gamma Technologies, “GT-Suite Engine Performance Application Manual,” 2016.

[56] T. Lanzanova, M. D. Nora, and H. Zhao, "Investigation of Early and Late Intake Valve Closure Strategies for Load Control in a Spark Ignition Ethanol Engine," SAE Int. J. Engines, vol. 10, no. 2017-01-0643, 2017.

[57] W. Guan, V. Pedrozo, H. Zhao, Z. Ban, and T. Lin, “Investigation of EGR and Miller Cycle for NOx Emissions and Exhaust Temperature Control of a Heavy-Duty Diesel Engine," SAE Tech. Pap., no. 2017-01-2227, 2017.

[58] P. Aleiferis, A. Taylor, K. Ishii, and Y. Urata, "The nature of early flame development in a lean-burn stratified-charge sparkignition engine," Combust. Flame, vol. 136, no. 3, pp. 283-302, Feb. 2004.

[59] H. Hanabusa, T. Kondo, K. Hashimoto, H. Sono, and M. Furutani, "Study on Homogeneous Lean Charge Spark Ignition Combustion," Oct. 2013.

[60] J. A. Caton, "Combustion phasing for maximum efficiency for conventional and high efficiency engines," Energy Convers. Manag., vol. 77, pp. 564-576, Jan. 2014.

[61] Y. Zhang, H. Zhao, M. Ojapah, and A. Cairns, “Effects of Injection Timing on CAl Operation in a 2/4-Stroke Switchable GDI Engine," SAE Int. J. Engines, vol. 5, no. 2, pp. 67-75, Aug. 2011. 
[62] S. Koda, K. Oda, M. Hirano, T. Hirano, and K. Akita, "Burning characteristics of methanol $\square$ water $\square$ air mixtures in a constant volume combustion vessel," Combust. Flame, vol. 46, pp. 17-28, Jan. 1982.

[63] K. Eisazadeh-Far, A. Moghaddas, J. Al-Mulki, and H. Metghalchi, "Laminar burning speeds of ethanol/air/diluent mixtures," Proc. Combust. Inst., vol. 33, no. 1, pp. 1021-1027, 2011.

[64] a. N. Mazas, B. Fiorina, D. a. Lacoste, and T. Schuller, "Effects of water vapor addition on the laminar burning velocity of oxygen-enriched methane flames," Combust. Flame, vol. 158, no. 12, pp. 2428-2440, Dec. 2011.

[65] B. M. Masum, H. H. Masjuki, M. a. Kalam, I. M. Rizwanul Fattah, S. M. Palash, and M. J. Abedin, "Effect of ethanolgasoline blend on NOx emission in SI engine," Renew. Sustain. Energy Rev., vol. 24, pp. 209-222, Aug. 2013.

[66] H. Zhao, $\mathrm{HCCl}$ and CAl engines for the automotive industry. Woodhead Pub., 2007. 
Appendix A

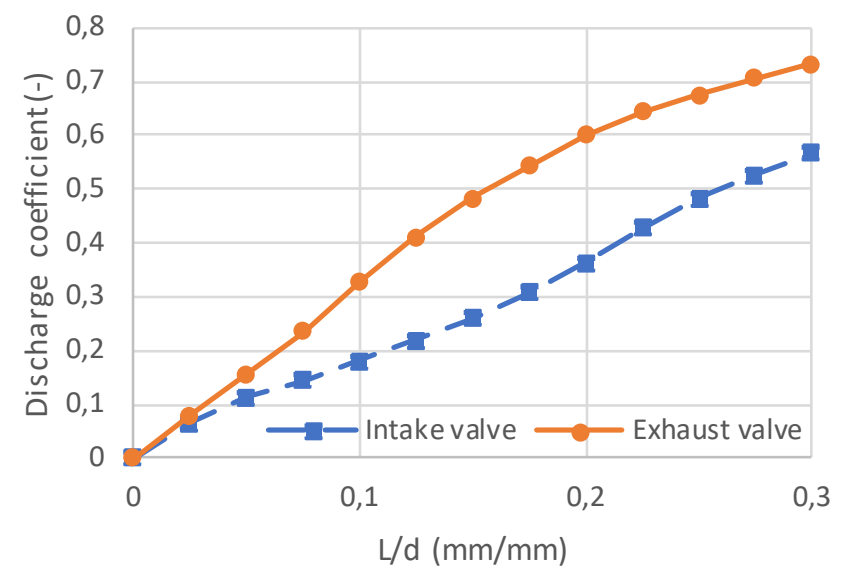

Figure A 1 - Valves discharge coefficients

Table A1 - Engine intake and exhaust manifold dimensions

\begin{tabular}{|l|c|c|c|c|c|}
\hline \multirow{2}{*}{} & diameter (mm) & lenght & \multicolumn{2}{c|}{ curvature } \\
\cline { 2 - 6 } & in & out & $(\mathrm{mm})$ & $\begin{array}{c}\text { bend rad } \\
(\mathrm{mm})\end{array}$ & $\begin{array}{c}\text { angle } \\
\text { (deg) }\end{array}$ \\
\hline \multicolumn{7}{|c|}{ Intake side } \\
\hline intake_1 & 40 & 40 & 145 & 35.36 & 45 \\
\hline itanke_2 & 40 & 40 & 60 & - & - \\
\hline intake_3 & 40 & 40 & 145 & 35.36 & 45 \\
\hline intake_4 & 40 & 40 & 30 & - & - \\
\hline int_port_split & 40 & 40 & 20 & - & - \\
\hline ports_int_X2 & 24 & 28 & 233.4 & - & - \\
\hline \multicolumn{7}{|c|}{ Exhaust side } \\
\hline ports_exh_X2 & 28 & 28 & 30 & - & - \\
\hline exh_port_split & 60 & 60 & 60 & - & - \\
\hline exh_1 & 50 & 50 & 400 & - & \\
\hline exh_2 & 60 & 50 & 80 & & \\
\hline exh_3 & 50 & 50 & 400 & & \\
\hline exh_4 & 50 & 50 & 126 & 80 & 90 \\
\hline exh_5 & 50 & 50 & 50 & - & \\
\hline exh_6 & 50 & 50 & 510 & & \\
\hline throttle & 50 & 50 & - & & \\
\hline exh_7 & 50 & 50 & 600 & & \\
\hline exh_8 & 50 & 50 & 126 & 80 & 90 \\
\hline exh_9 & 50 & 50 & 900 & - & - \\
\hline muffler_1 & 210 & 210 & 350 & & \\
\hline muffler_2 & 210 & 210 & 250 & & \\
\hline muffler_3 & 210 & 210 & 400 & & \\
\hline muffler_4 & 45 & 45 & 10000 & & \\
\hline
\end{tabular}



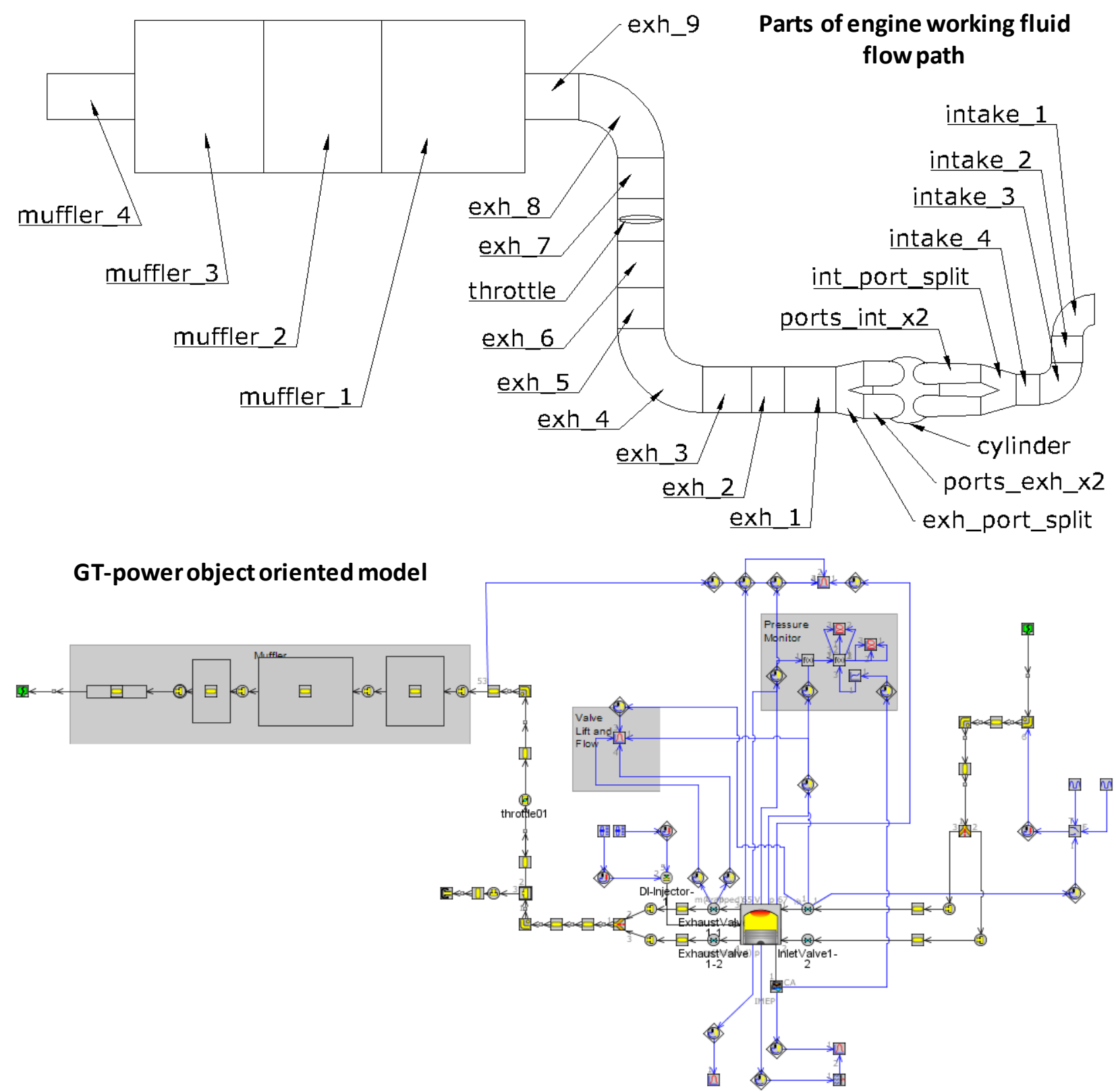

Figure A 2 -Engine piping dimensional schematics (not in scale) 